\title{
Comparing The Models SARIMA, ANFIS And ANFIS- DE In Forecasting Monthly Evapotranspiration Rates Under Heterogeneous Climatic Conditions
}

\section{Pouya Aghelpour}

Bu-Ali Sina University

Vahid Varshavian ( $\sim$ v.varshavian@basu.ac.ir)

Bu Ali Sina University Faculty of Agriculture https://orcid.org/0000-0002-9705-3066

Zahra Hamedi

University of Birmingham

\section{Research Article}

Keywords: Differential Evolution, ANFIS, Stochastic, ARIMA, Time series prediction, Reference Crop Evapotranspiration

Posted Date: August 17th, 2021

DOl: https://doi.org/10.21203/rs.3.rs-781601/v1

License: (c) (i) This work is licensed under a Creative Commons Attribution 4.0 International License. Read Full License 


\section{Comparing the models SARIMA, ANFIS and ANFIS-DE in}

2 forecasting monthly evapotranspiration rates under heterogeneous climatic conditions

5 Pouya Aghelpour ${ }^{\text {a }}$, Vahid Varshavian ${ }^{\mathrm{b} *}$, Zahra Hamedi

6 (a) MSc graduated of agricultural meteorology, Department of Water Engineering, Faculty of Agriculture,

7 Bu-Ali Sina University, Hamedan, Iran (Email: p.aghelpour@agr.basu.ac.ir; ORCID:

$8 \quad$ https://orcid.org/0000-0002-5640-865X)

9 ( $\left.b^{*}\right)$ Assistant Professor of agricultural meteorology, Department of Water Engineering, Faculty of 10 Agriculture, Bu-Ali Sina University, Hamedan, Iran (Email: v.varshavian@basu.ac.ir; ORCID:

11 https://orcid.org/0000-0002-9705-3066)

12 (C) MSc graduated of Computer Science, Computer Science Department, University of Birmingham,

13 Birmingham, UK (Email: zahra.hamedi179@gmail.com; ORCID: https://orcid.org/0000-0001-5279-

$14 \quad \underline{500 X})$

15 *Corresponding author name: Vahid Varshavian

16 *Corresponding author Email: v.varshavian@basu.ac.ir

17 


\section{Comparing the models SARIMA, ANFIS and ANFIS-DE in}

21 forecasting monthly evapotranspiration rates under heterogeneous climatic conditions

24 Abstract

25 Reference crop evapotranspiration (ET0) is one of the most important hydro-climatological components which directly affects agricultural productions, and its forecasting is critical for water managers and irrigation planners. In this study, adaptive neuro-fuzzy inference system (ANFIS) model has been hybridized by differential evolution (DE) optimization algorithm as a novel approach to forecast monthly ET0. Furthermore, this model has been compared with the classic stochastic time series model. For this, the ET0 rates were calculated on monthly scale during 19952018, based on FAO-56 Penman-Monteith equation and meteorological data including: minimum air temperature, maximum air temperature, mean air temperature, minimum relative humidity, maximum relative humidity \& sunshine duration. The investigation was performed on 6 stations in different climates of Iran, including: Bandar Anzali \& Ramsar (per-humid), Gharakhil (subhumid), Shiraz (semi-arid), Ahwaz (arid) and Yazd (extra-arid). The models' performances were evaluated by the criteria percent bias (PB), root mean squared error (RMSE), normalized RMSE

37 (NRMSE) and Nash-Sutcliff (NS) coefficient. Surveys confirm the high capability of the hybrid ANFIS-DE model in monthly ET0 forecasting; so that the DE algorithm was able to improve the accuracy of ANFIS, by $16 \%$ on average. Seasonal autoregressive integrated moving average (SARIMA) was the most suitable pattern among the time series stochastic models, and superior

41 compared to its other competitors. Consequently, due to the simplicity and parsimony, the 
42 SARIMA was suggested more appropriate for monthly ET0 forecasting in all the climates.

43 Comparison between the different climates confirmed that the climate type significantly affects

44 the forecasting accuracies: it's revealed that all the models work better in extra-arid, arid and semi45 arid climates, than the humid and per-humid areas.

46 Keywords: Differential Evolution; ANFIS; Stochastic; ARIMA; Time series prediction;

\section{Reference Crop Evapotranspiration}

\section{Introduction}

49 The process of water parting the surface of moist soil is called evaporation, whereas this 50 phenomenon from leaves' pores is called transpiration. Since recognizing these two phenomena 51 on farms is not easy, they are to be considered as one integrated single variable referred to as 52 "evapotranspiration". On the other hand, evapotranspiration is considered as the water requirement 53 of plants, so its measurement is very important in all agricultural and irrigation projects. The 54 amount of evapotranspiration is measured by a lysimeter. Due to the sensitivity of the lysimeter, 55 there is a need for the presence of a technician expert on-site in order for the lysimeter to be 56 continuously calibrated. Consequently, if good care is not taken, the recorded cases of lysimeter 57 may have errors. As a remedy, the International Commission on Irrigation and Drainage (ICID) and World Meteorological Organization (WMO) have recognized the FAO-56 Penman-Monteith 59 equation (FAO-56 PM), as a suitable alternative to the lysimeter (Allen et al., 1998); which can 60 use several meteorological variables to estimate the evapotranspiration rate with an acceptable 61 accuracy.

62 In recent years, despite the presence of some well-known mathematical models such as Penman63 Monteith, Thornthwaite, Hargreaves-Samani, Blaney-Criddle, etc., the black-box artificial 
64 intelligence (AI) models have been able to show acceptable accuracy in estimating

65 evapotranspiration. For example, Mohammadi \& Mehdizadeh (2020) and Ahmadi et al. (2021) by carrying out a survey on the arid and semi-arid regions of Iran found that in the complete absence

67 of meteorological variables (which are required to use the Penman method), the AI models are able to estimate evapotranspiration with reasonable accuracy, by the least available meteorological

69 variables. They also contended that integrating AI models with bio-inspired optimization 70 algorithms can significantly increase the accuracy of evapotranspiration estimation. In Australia, 71 AIs were able to provide an accurate estimate of evapotranspiration with only temperature and 72 wind speed as available variables (Falamarzi et al., 2014); which in the absence of complete 73 meteorological variables can be considered as suitable alternative for the FAO-56 PM model. Also, 74 in cases such as Kumar et al. (2002), the validation of the estimated evapotranspiration from neural 75 networks using lysimeter measured evapotranspiration values, and comparing them with the 76 outputs of the FAO-56 PM model showed that AIs can be a better estimator for evapotranspiration.

77 Reference crop evapotranspiration (ET0) is one of the main components of the hydrological cycle 78 associated with agricultural systems. Accurate estimation and prediction of ET0 is very important 79 in water resources management, irrigation planning, and determining the water needs of plants. 80 Forecasting the evapotranspiration rates, through providing information on the future status of 81 evapotranspiration at different time scales can be of great help in making appropriate decisions, 82 planning as well as applying management methods of water resources. Data-driven models such 83 as stochastic and artificial intelligence methods are efficient approaches that have shown good 84 performance in modeling and predicting hydrometeorological variables in recent years (Aghelpour 85 et al., 2021c; Mohammadi et al., 2020; Aghelpour et al. 2020b). Karbasi (2018) used AIs in 86 forecasting ET0 for 1, 2, 3, 7, 10, 14, 18, 24, and 30 days' horizons. Karbasi (2018) concluded that 
87 the predictions' accuracy was desirable and showed that with increasing the forecast horizon, the 88 forecasting accuracy decreases. A comparison between stochastic and artificial intelligence methods in Spain revealed that both model types predicted weekly evapotranspiration effectively 90 (Landeras et al., 2009). Lucas et al. (2020) compared the Seasonal Autoregressive Integrated 91 Moving Average (SARIMA) stochastic model with the Convolutional Neural Network (CNN) 92 model in order to predict daily evapotranspiration in Brazil. They concluded that the CNN model 93 is able to provide a more accurate prediction of evapotranspiration than the SARIMA model. In 94 opposite, in the Tamil Nadu of India, a comparison was made between artificial intelligence and 95 stochastic methods and stochastic models were introduced more appropriate for predicting ET0 (Kishore \& Pushpalatha, 2017). Predicting evapotranspiration especially in areas such as Iran 97 which facing limited water resources, is doubly important for the determination of the cultivation pattern, and proper management of water and soil resources. In Iran, these two types of numerical 99 models (stochastics and AIs) have been used to predict ET0. Ashrafzadeh et al. (2020) used the 100 SARIMA, Group Method of Data Handling (GMDH), and Support Vector Machine (SVM) models, to predict ET0 in humid areas of the Caspian Sea's southern margin. They evaluated the 102 accuracy of the models and showed that the mentioned models are able to predict the ET0 value 103 for the next 2 years, with the same suitable accuracy as the train-test period.

104 The Adaptive Neuro-Fuzzy Inference System (ANFIS) model is one of the most efficient AI 105 methods that has been used in both simple and hybridized forms, for hydrological and 106 meteorological modeling. ANFIS model showed its acceptable performances, in solar radiation 107 estimation (Üstün et al., 2020; Benmouiza \& Cheknane, 2019; Halabi et al., 2018; Khosravi et al., 108 2018), pan evaporation estimation (Adnan et al., 2019; Guven \& Kisi, 2013; Keskin et al., 2009), 109 drought forecasting (Aghelpour et al., 2021a; Aghelpour et al., 2021b; Aghelpour et al., 2020a; 
Aghelpour et al., 2020c; Kisi et al., 2019), river flow forecasting (Aghelpour \& Varshavian, 2020; Allawi et al., 2018), rainfall forecasting (Mekanik et al., 2016; Yaseen et al., 2018; Aghelpour et al., 2021d) and wind speed forecasting (Maroufpoor et al., 2019). However, they are rarely used in evapotranspiration prediction studies. The combination of bio-inspired optimization algorithms has improved the performances of AIs in most cases, significantly (Deo et al., 2018; Aghelpour et al., 2019; Paham et al., 2021; Aghelpour \& Varshavian, 2021; Mohammadi et al., 2021). These algorithms that use complex evolutionary methods can optimally enhance the parameters of AIs, and significantly increase the accuracy of estimates and predictions (Moazenzadeh \& Mohammadi, 2019; Ashrafzadeh et al., 2019; Ashrafzadeh et al. al., 2020; Aghelpour et al., 2020c).

The present study intends to use the ANFIS model to predict the reference evapotranspiration and compare it with the classical SARIMA stochastic model. Moreover, as a novelty, the Differential Evolution (DE) algorithm (a bio-inspired algorithm) which is hybridized with the ANFIS model, has been used as ANFIS-DE to optimize and improve the ANFIS's prediction accuracy. In this study, stations from different climates (from extra-arid to per-humid) are studied and for the first time, the effect of climate type is also investigated on the accuracy of the models predicting ET0; which is another novelty aspect of the current research.

\section{Materials and methods}

\subsection{Data and areas under investigation}

Iran is located in the Middle East, on the dry belt of the earth. Consequently, it is facing limited water resources in human life's different sectors, such as agriculture. According to De-Martonne climatic zoning, Iran has 28 different climatic classes (Rahimi et al., 2013; Aghelpour et al., 2020a). The majority of regions of Iran have arid (central desert, southwest, and southwest of the 
133 country) and semi-arid climates (The Zagros Mountains in the west and northwest of the country

134 as well as northeastern regions), and only small areas of Iran have humid climates (Southern shore

135 of the Caspian Sea in the north). The rate of evapotranspiration, which is affected by different

136 meteorological factors, varies in different climatic zones. For example, in arid regions such as

137 Ahwaz, the range of ET0 is between 40 and $350 \mathrm{~mm}$ per month, while in humid climates like

138 Ramsar, the ET0 varies between 20 and $158 \mathrm{~mm}$ per month. This paper aims to investigate the

139 effect of the type of the climate on the accuracy of models predicting evapotranspiration. For this,

140 six synoptic stations from different climates of Iran are considered (Figure 1).

142 Three stations were selected from humid and sub-humid areas of northern Iran (on the southern 143 margin of the Caspian Sea), and the other three stations were selected from arid and semi-arid 144 areas in central and southwestern parts of Iran. Most of the agricultural lands in the northern humid 145 areas are under rice cultivation and the horticultural lands in this area are often under citrus 146 cultivation. In arid and semi-arid regions of the southern parts of Iran, the main agricultural crops 147 include wheat and maize, and the important horticultural crops are grapes and pistachios. A 148 summary of information on the climatic zones in this study, stations, and common products in 149 them is shown in Table 1.

151 The data used in this paper include monthly meteorological data and belong to the period 1995152 2018. These data include minimum air temperature (Tmin), maximum air temperature (Tmax), 153 mean air temperature (Tmean), minimum relative humidity (RHmin), maximum relative humidity 154 (RHmax) and sunshine duration (SSD), which are prepared on a monthly scale of the Iranian 
155 Meteorological Organization (IRIMO). Using these data and FAO-56 PM model, the amount of 156 monthly evapotranspiration was estimated in the 6 mentioned stations. The "Evapotranspiration" 157 package in R software was used to estimate the evapotranspiration rates, based on the FAO-56 PM 158 method. For modeling, the period under study was divided into two parts of training and testing, 159 which include $75 \%$ (the first 18 years) and 25\% (the remaining 6 years), respectively. The 160 characteristics of the meteorological data as well as the estimated evapotranspiration data are 161 shown in Table 2.

$<$ Table 2. here>

\subsection{Time series model}

164 A time series is a set of recorded observations of a variable such as $\mathrm{X}_{\mathrm{i}}$ overtime in the form of $\mathrm{X}_{1}$, $165 X_{2}, X_{3}, \ldots, X_{N}$ between which the time interval is equal (Gutam \& Sinha, 2016). Time series models are kind of stochastic models that work based on regression coefficients and use the time

167 lags of the target variable, as the model's input variable. These models include Autoregressive 168 (AR), Integrated (I), and moving average (MA) components. They are shown in an integrated state 169 known as Autoregressive Integral Moving Average (ARIMA). The Seasonal ARIMA (SARIMA) 170 model is a model that can be used for numerical simulation of the stochastic behavior of periodic

171 time series. In other words, SARIMA is a linear parametric stochastic model which can be used to 172 model and predict variables, which have seasonal autocorrelations. The cross form of this model 173 is shown as $\operatorname{SARIMA}(\mathrm{p}, \mathrm{d}, \mathrm{q}) \times(\mathrm{P}, \mathrm{D}, \mathrm{Q})_{\omega}$; in which $\omega$ is the periodicity; $\mathrm{p}, \mathrm{d}$, and $\mathrm{q}$ are the non174 seasonal degrees of autoregressive, differencing and moving average, respectively; P, D, and Q 175 are the seasonal degrees of autoregressive, differencing and moving average, respectively. The 176 general form of this model is shown below: (Salas et al, 1980): 
Eq. $1 \quad \Phi_{P}\left(B^{\omega}\right) \phi_{p}(B) \nabla_{\omega}^{D} \nabla^{d} X_{t}=\theta_{q}(B) \Theta_{Q}\left(B^{\omega}\right) \varepsilon_{t}$

177 In this formula $X_{t}$ is a stochastic variable as the target and $\varepsilon_{t}$ is a normal random variable with 178 mean $\mu$ and variance $\sigma_{\varepsilon}^{2}$, as a residual. Parameters of B including $\Phi, \phi, \nabla_{\omega}^{D}, \nabla^{d}, \Theta, \theta$, represent the 179 backward operators associated with seasonal autoregressive, non-seasonal autoregressive, 180 seasonal differencing and non-seasonal differencing, seasonal moving average and non-seasonal 181 moving average, respectively. Whose equations are described in equations 2 to 7 (Salas et al, 182 1980).

Eq. $2 \quad \Phi_{P}\left(B^{\omega}\right)=\left(1-\Phi_{1} B^{\omega \times 1}-\cdots-\Phi_{P} B^{\omega \times P}\right)$

183

Eq. $3 \quad \phi_{p}(B)=\left(1-\phi_{1} B^{1}-\cdots-\phi_{p} B^{p}\right)$

184

Eq. $4 \quad \nabla_{\omega}^{D}=\left(1-B^{\omega}\right)^{D}$

185

Eq. $5 \quad \nabla^{d}=(1-B)^{d}$

186

Eq. $6 \quad \Theta_{Q}\left(B^{\omega}\right)=\left(1-\Theta_{1} B^{\omega \times 1}-\cdots-\Theta_{Q} B^{\omega \times Q}\right)$

187

Eq. $7 \quad \theta_{q}(B)=\left(1-\theta_{1} B^{1}-\cdots-\theta_{q} B^{q}\right)$

188 In this research, the Minitab software and the SARIMA model have been used to simulate and 189 predict evapotranspiration time series. 
ANFIS model has the ability to make relationships between input and output data using fuzzy rules and to learn from a neural network in order to generate input structure for a system. ANFIS model designs and creates non-linear maps to define relationships between input and output spaces by employing Artificial Neural Network (ANN) and fuzzy logic, which is known as a neuro-fuzzy system. Fuzzy systems include three different parts, namely fuzzification, inference engine, and defuzzification. Fuzzy rules are achieved by utilizing fuzzy inference systems. A Fuzzy inference system consists of two different inferences, namely Mamdani and Sugeno. They both work in an excellent fashion when they are combined with an optimization algorithm and adaptive techniques (Khosravi et al., 2018). In this paper, we use Sugeno inference. Figure 2 shows the structure of the ANFIS model. These two equations are the base rules of Sugeno inference:

Eq. 8 Rule 1: if $x$ is $A_{1}$ and $y$ is $B_{1}$, then $f_{1}=p_{1} x+q_{1} y+r_{1}$

Eq. 9

Rule 1: if $x$ is $A_{2}$ and $y$ is $B_{2}$, then $f_{2}=p_{2} x+q_{2} y+r_{2}$ ANFIS model contains different layers. Layer one, in this model, is the fuzzification layer. Each node receives a signal and then transfers it to the next layer. The following equation describes the cells outputs $\left(O_{1}^{i}\right)$ (Khosravi et al., 2018; Haznedar and Kalinli, 2016):

$$
\text { Eq. } 10 \quad O_{1}^{i}=\mu_{A_{i}}(x) ; \quad i=1,2
$$

$207 \mu_{A_{i}}$ is related to Membership Function (MF). $A_{i}$ is linguistic variable and it is related to node 208 function. The following equation shows the common formula for $\mu_{A_{i}}$ 
Eq. $11 \quad \mu_{A_{i}}(x)=\exp \left\{-\left[\left(\frac{x-c_{i}}{a_{i}}\right)^{2}\right]^{b_{i}}\right\}$

209 In this equation, $\mathrm{x}$ is input and $a_{i}, b_{i}, c_{i}$ are premise parameters. Layer 2 is called the rule layer

210 which is obtained by membership degrees. All the output nodes establish the firing strength of a

211 fuzzy rule.

$$
\text { Eq. } 12 \quad O_{2}^{i}=w_{i}=\mu_{A_{i}}(x) \cdot \mu_{B_{i}}(y) ; \quad i=1,2
$$

212 Layer 3 is the normalization layer. In this layer, all the nodes are fixed and they are tagged with

213 N. The rule's firing strength to the sum of all rules' firing strengths is the ratio that is calculated by

214 the $i^{\text {th }}$ node in the normalization layer.

$$
\text { Eq. } 13 \quad O_{3}^{i}=\overline{w_{l}}=\frac{w_{i}}{w_{1}+w_{2}} ; \quad i=1,2
$$

215 The defuzzification layer is the layer 4 of ANFIS model. Each rule uses the value of the previous

216 layer to compute the output value.

$$
\text { Eq. } 14 \quad O_{4}^{i}=\bar{w}_{l} f_{i}=\bar{w}_{l}\left(p_{i} x+q_{i} y+r_{i}\right) ; \quad i=1,2
$$

217 In this equation, $\overline{w_{l}}$ comes from the previous layer, namely layer $3 . \overline{w_{l}}$ is a normalized firing 218 strength and $p_{i}, q_{i}$, and $r_{i}$ are the consequent parameters. Layer 5 is called the sum layer. By 219 summing the output values of the rules that come from the previous layer, the final output of the 220 ANFIS model is calculated.

Eq. 15

$$
O_{5}^{i}=\text { overall output }=\sum_{i} \bar{w}_{l} f_{i}=\frac{\sum_{i} w_{i} f_{i}}{\sum_{i} w_{i}} \quad i=1,2
$$

221 To implement the ANFIS model, MATLAB software is used in this study.

222 To summarize, the ANFIS model contains two sets of parameters: premise parameters and 223 consequence parameters. Premise parameters are input parameters of MFs and their aim is to 
224 specify the shape and the location of the input MFs (parameters of input MFs). Consequence

225 parameters are output parameters of MFs (parameters of output MFs) (Jang, 1993). To estimate

226 these parameters, classical ANFIS uses the least square (LS) methods. However, in the current

227 research, we have developed a novel ANFIS-DE model, which uses the meta-heuristic Differential

228 Evolution (DE) algorithm to estimate ANFIS's sets of parameters.

2.4. Differential Evolution (DE) optimization algorithm

Although Differential Evolution (DE) uses basic optimized operations such as mutation, crossover,

231 and selection, it is an impressive and powerful optimization algorithm. One of the privileges of

232 this algorithm is that it has parallel search methods and uses NP and also it has D-dimensional

233 vectors of parameters. The advantage of these vectors is that they do not change during the

234 minimization procedure. DE performs a population process for each generation G. First, one

235 population vector is randomly initialized including the parameters and this probability distribution

236 is uniformed. When preliminary solution is achieved, DE algorithm calculates the difference

237 between the weights of two population vectors and assigns it to the third vector in order to produce

238 new parameter vectors, which is known as the mutation operation (Halabi et al., 2018):

$$
\text { Eq. } 16 \quad v_{i, G+1}=x_{i, G}+F\left(x_{r 2, G}-x_{r 3, G}\right)
$$

239 According to $v_{i, G+1}$, these mutant vectors, $x_{i}, G$ and $i=1,2,3, \ldots, N P$ are created, while $r 1, r 2$, 240 and $r 3$ are randomly integers and NP is selected from this distribution: integers $\in[1,2,3, \ldots, N P]$.

241 Moreover, $I$ and $F$ are real values and they are different from each other $\in[1,2,3, \ldots, N P]$.

242 During the mixing process which is also called crossover operation, parameters of the mutated

243 vector are mixed with other vector parameters to create the trial vector. The following equations 244 describe this mixing process: 


$$
\text { Eq. } 17 \quad u_{i, G+1}=\left(u_{1 i, G+1}, u_{2 i, G+1}, \ldots, u_{d i, G+1}\right)
$$

$$
\text { Eq. } 18 \quad u_{j i, G+1}= \begin{cases}v_{j i, G+1} ; & \text { if } \operatorname{randb}(j) \leq C R \text { or } j=\operatorname{rnbr}(i) \\ x_{j i, G+1} ; & \text { if } \operatorname{randb}(j)>C R \text { or } j \neq \operatorname{rnbr}(i)\end{cases}
$$

246 In this equation, $u_{i, G+1}$ is the trailer and $x_{i, G}$ is the target vector, where $u_{i, G+1}$ and $x_{i, G}$ are the 247 trailer and target vectors, respectively. $\operatorname{randb}(j)$ is the $\mathrm{J}^{\text {th }}$ uniform random evaluation $\in[0.1]$, $248 \operatorname{rnbr}(i)$ is a random value index $\in[1,2,3, \ldots, d]$ and $C R$ is crossover constant which is determined 249 by users. The selection operation is the last operation. The trial vector costs a lower cost function 250 than the target vector. Therefore, the selection operation uses the trial vector as a target value for 251 the next generation. $N P$ competitions are considered like one generation procedure as each 252 population vector has to serve once as the target vector. Complementary descriptions about the DE 253 optimization algorithm can be found in Storn \& Price (1997) and Halabi et al. (2018). The DE 254 algorithm flowchart is illustrated in Figure 3.

256 In this paper, the DE algorithm is implemented by coding in MATLAB software's environment. 257 The trial and error method is used to choose the best operators of DE to optimize the ANFIS model. 258 They are illustrated in Table 3.

$<$ Table 3. here > 2.5.Evaluating the accuracy of the predictions

261 This study uses six criteria to evaluate the performance of the models: Root Mean Square Error 262 (RMSE), Normalized RMSE (NRMSE), Percent Bias (PB), Pearson correlation coefficient (R), coefficient of determination $\left(\mathrm{R}^{2}\right)$, and Nash- Sutcliff coefficient (NS). In general, these criteria are 
264 used to compare the accuracy of different models with each other. Furthermore, they are used to

265 compare the accuracy of models in different climates. To calculate them, we need two series of

266 predicted and observed evapotranspiration data. Their equations are as follows.

Eq. 19

$$
R M S E=\sqrt{\frac{1}{n} \sum_{i=1}^{n}\left(E T O_{i}-E T P_{i}\right)^{2}} ; \quad 0<R M S E<+\infty
$$

267

Eq. $20 \quad P B=\sum_{i=1}^{n}\left(\frac{E T O_{i}-E T P_{i}}{E T O_{i}}\right) ; \quad-\infty<P B<+\infty$

268

Eq. 21

$$
R=\frac{\sum_{i=1}^{n}\left(E T O_{i}-\overline{E T O}\right)\left(E T P_{i}-\overline{E T P}\right)}{\sqrt{\sum_{i=1}^{n}\left(E T O_{i}-\overline{E T O}\right)^{2}} * \sqrt{\sum_{i=1}^{n}\left(E T P_{i}-\overline{E T P}\right)^{2}}} ; \quad-1<R<1
$$

269

Eq. 22

$$
R^{2}=\left[\frac{\sum_{i=1}^{n}\left(E T O_{i}-\overline{E T O}\right)\left(E T P_{i}-\overline{E T P}\right)}{\sqrt{\sum_{i=1}^{n}\left(E T O_{i}-\overline{E T O}\right)^{2}} * \sqrt{\sum_{i=1}^{n}\left(E T P_{i}-\overline{E T P}\right)^{2}}}\right]^{2} ; \quad 0<R^{2}<1
$$

270

Eq. 23

$$
N R M S E=\frac{\sqrt{\frac{1}{n} \sum_{i=1}^{n}\left(E T O_{i}-E T P_{i}\right)^{2}}}{E T O_{\max }-E T O_{\min }} ; \quad 0<N R M S E<+\infty
$$

271

Eq. 24

$$
N S=1-\frac{\sum_{i=1}^{n}\left(E T O_{i}-E T P_{i}\right)^{2}}{\sum_{i=1}^{n}\left(E T O_{i}-\overline{E T O}\right)^{2}} ; \quad-\infty<N S<1
$$


$272 E T O_{i}$ shows the amount of observed evapotranspiration of the $\mathrm{i}^{\text {th }}$ month, ETP $P_{i}$ is the amount of

273 evapotranspiration predicted in the $\mathrm{i}^{\text {th }}$ month, $\overline{E T O}$ shows the mean of observational

274 evapotranspiration, $\overline{E T P}$ represents the average of the predictive evapotranspiration ، $E T O_{\max }$ is

275 the maximum of the observational evapotranspiration, and finally $E T O_{\min }$ is the minimum of the

276 observational evapotranspiration. According to the defined range for these criteria, the closer the

277 RMSE, PB and NRMSE are to zero, and the closer NS, R, and $\mathrm{R}^{2}$ are to one, the better the model

278 performance is. Another point about NRMSE is that it has 4 intervals in terms of evaluating the

279 quality of models: 1) NRMSE $>0.3$ poor performance, 2) $0.2<$ NRMSE $<0.3$ average performance

280 3) $0.1<$ NRMSE $<0.2$ good performance and 4) $0<$ NRMSE $<0.1$ excellent performance.

281 The general process of modeling and predicting the evapotranspiration time series in this paper is 282 shown as a flowchart in Figure 4.

$<$ Figure 4 here $>$

\section{Results}

\subsection{Modeling and evaluating the predictions}

286 In this study, ET0's monthly time lags were considered as input to the models. Therefore, 287 Autocorrelation Function (ACF) diagrams for different stations were considered (Figure 5), which 288 show the extent and significance of the correlation of the variable with its previous steps' amounts.

291 ET0 time series are periodic and have a 12 months' periodicity. To moderate this seasonal trend, 292 several degrees of seasonal differentiation with a lag of 12 months (equal to the periodicity) were 293 considered. Investigations showed that seasonal differentiation of order "one" has the best 
consistency with ET0 data. As a result, the SARIMA model is modified as the SARIMA pattern SARIMA $(p, 0, q)(P, 1, Q)_{12}$. Moreover, when the time lag increases, the significance threshold of correlation (dashed line) increases and more than three return periods (36 months), it reaches a point that is practically logical not to use them as inputs. Therefore, a maximum lag of 36 months is considered as inputs for all models. In the SARIMA model, this includes seasonal autoregressive and moving average degrees $(\mathrm{P} \& \mathrm{Q})$, which is equal to 1,2 , and 3 . These degrees and also the non-seasonal degrees of autoregressive and moving average ( $p \&$ q) were all tested, and their best performance was selected for each station and reported in Table 4. Simple and hybrid ANFIS models (ANFIS \& ANFIS-DE) were implemented based on the fuzzy c-means (FCM) clustering method. Lags of 1, 6, 12, 18, 24, 30, and 36 months were also considered as inputs to these AI models.

$<$ Table 4. here>

In Table 4, the predictions of all three models were evaluated by the mentioned evaluation metrics. Since the test section actually shows the validity of the models, the test section is also discussed in the interpretations of this section. At first, it can be seen that in all stations, the R coefficients are very high, which indicates the optimal performance of the models in predicting monthly ET0 (the minimum value of $\mathrm{R}$ is equal to 0.949 , which belongs to the simple ANFIS model in Ramsar station). Additionally, the amount of PB in all cases is very small (close to zero); which confirms the lack of significant under/overestimation and consequently the excellent performance of the models. According to Table 4, in all stations, the SARIMA linear model has superior performance than the other two models, and the weakest performance among the models belongs to the simple ANFIS model. The DE algorithm in combination with the ANFIS model (ANFIS-DE), was able to increase the prediction accuracy for ANFIS by an average of $15.8 \%$. The lowest prediction error 
317 belongs to the SARIMA model at Shiraz station with RMSE $=7.918 \frac{\mathrm{mm}}{\mathrm{month}}$. The highest prediction 318 error is reported in Ahwaz station with RMSE $=16.906 \frac{\mathrm{mm}}{\mathrm{month}}$, which belongs to the simple ANFIS 319 model.

\subsection{Comparison between the models}

321 Scatter plots are used for graphical illustration of the correlation between the predicted and actual 322 values of monthly ET0 (figure 6).

$<$ Figure 6. here>

324 In Figure 6, the horizontal axis of the graphs represents the observed ET0 data, and the vertical 325 axis represents the predictions presented by the models. This figure shows that at all stations, the 326 slope of the fitted regression line between the observed-predicted data samples is very small 327 associated with the $\mathrm{X}=\mathrm{Y}$ line. The points are well concentrated around their regression line, and 328 this concentration is more on the diagrams related to the SARIMA model than the other two 329 models. On the other hand, the $\mathrm{R}^{2}$ coefficient shows that the SARIMA linear model offers a better 330 prediction than the other two nonlinear and complex models, ANFIS and ANFIS-DE. Also, 331 ANFIS-DE predictions show better correlations compared to simple ANFIS. The diagrams in 332 Figure 6 show that the weakest performance belongs to the predictions of ANFIS in Ramsar $\left(\mathrm{R}^{2}=\right.$ 333 0.901), and the best performance belongs to the predictions of SARIMA at Yazd station $\left(\mathrm{R}^{2}=\right.$ 334 0.984). In order to compare the models, the Taylor diagram is also represented for each station 335 (Figure 7). 
337 This diagram (Figure 7) is able to simultaneously check the correlation, the error, and also to 338 compare their standard deviations, between the outputs of several models vs their observational 339 values. In these diagrams, point $\mathrm{O}$ is an indicator of observational data, and points $\mathrm{A}, \mathrm{B}$, and $\mathrm{C}$ are 340 the indicators of the SARIMA, ANFIS, and ANFIS-DE models, respectively. At all stations, point 341 A is located the closest to point O, confirming the superiority of the SARIMA model. After that, 342 ANFIS-DE (point C) and ANFIS (point B) models are in the second and third places, respectively. 343 The best position of points A, B, and C belongs to Shiraz station, where these points are located 344 between two circles $\mathrm{RMSE}=5 \frac{\mathrm{mm}}{\mathrm{month}}$ and $\mathrm{RMSE}=10 \frac{\mathrm{mm}}{\mathrm{month}}$, and around the radius $\mathrm{R}=0.99$. At 345 Yazd station, a similar situation to Shiraz is observed. The weakest points' position can belong to 346 Bandar Anzali station; where points A, B and C are farthest from point O, between circles of $347 \mathrm{RMSE}=10 \frac{\mathrm{mm}}{\text { month }}$ and $\mathrm{RMSE}=15 \frac{\mathrm{mm}}{\text { month }}$, and between two radii of $\mathrm{R}=0.99$ and $\mathrm{R}=0.95$. 348 Furthermore, comparing the standard deviations between outputs and the observations, reveals that 349 the points of the models, especially point A, are in a very good position relative to the quadrant 350 close to point O. This shows that the models, especially SARIMA, have been able to show good 351 ability in estimating the standard deviation of actual ET0 values.

\subsection{Comparison of ET0 prediction accuracy among different climates}

353 In general, the comparison between the stations in Figure 7 represents that the humid stations are 354 located in weaker ranges of error and correlation, than the arid stations. Also, according to Figure 3556 , in humid and sub-humid climates, the $\mathrm{R}^{2}$ value resulted from the SARIMA model is in the range 356 of $0.95-0.96$, while in arid and semi-arid regions, it is in the range of $0.97-0.98$. Therefore, it is

357 evident that ET0 is slightly better predicted in arid areas. However, due to the different range of 
ET0 data in different climates (Table 2), it is better to consider the normalized RMSE (NRMSE) criterion at stations for evaluation (Figure 8).

$<$ Figure 8. here>

In Figure 8, the NRMSE and NS criteria for the test period were plotted together as a combograph. This diagram is drawn separately for all models at all stations. At first, it can be seen that all models have a NS value greater than 0.9 , which confirms the very good prediction of ET0 by the models. Moreover, the NRMSE value in all stations is less than 0.1. According to the quality classes defined for NRMSE (Aghelpour \& Varshavian, 2020), the predictions for all climates in this study are considered very reasonable. The visible trend of NS and NRMSE is similar across stations. Both criteria indicate a better prediction of ET0 in arid and semi-arid climates. In other words, if the NS level is increased at a station, the NRMSE level will decrease at the same station (which is well illustrated in the combo-graph). Therefore, it can be said that both criteria achieved similar results in comparing the accuracy of ET0 prediction among the climates. For example, in the ANFIS-DE model for humid and sub-humid stations, the NRMSE is between $0.07-0.09$ and the NS is between $0.93-0.95$, while for arid and semi-arid stations, NRMSE is between 0.04 0.06 and NS is between 0.97 - 0.98. In the combo-graph belonging to the SARIMA model, the NRMSE value for humid and sub-humid areas is between $0.06-0.08$ and the NS value is between $0.94-0.96$, while for arid and semi-arid areas, the NRMSE is between $0.04-0.05$ and the NS is between $0.98-0.99$. The comparison of the models is similar to the previous diagrams and tables; which reported the SARIMA model more appropriate. The predictions provided by the models can also be graphically seen in time-series plots (Figure 9), to see the overlaps.

<Figure 9. here> 
381 Research on the use of AIs to estimate and predict the reference evapotranspiration, as in this 382 paper, have evaluated the results of these models as favorable (Ahmadi et al., 2021; Ashrafzadeh 383 et al., 2020; Adamala et al., 2018; Abrishami et al., 2019). Also, the desirability of the accuracy of 384 time series models in the current study is similar to the research of Gautam \& Sinha (2016), 385 Landeras et al. (2009), Psilovikos \& Elhag (2013), Mossad \& Alazba (2016), and Bouznad et al. 386 (2020), that have been conducted in different climatic regions. The superiority of time series 387 models over AIs in ET0 forecasting in Iran, has also been reported in Ashrafzadeh et al. (2020); 388 however, their study only addressed the humid northern climate. Additionally, Ashrafzadeh et al. 389 (2020) used non-hybridized models of artificial intelligence; while the current research showed 390 that the novel hybrid ANFIS-DE model can significantly increase the accuracy of the simple ANFIS model. In Brazil, however, AIs provided a relatively more accurate prediction of ET0 than 392 time series models did (Lucas et al., 2020), which contradicts the results of the current study. The 393 reason for this contradiction could be due to the differences between the climatic conditions of the 394 studies' regions.

395 In comparison, between the climates of the present study, the geographical location as well as the 396 physical systems involved can be factors influencing the accuracy of ET0 prediction. For example, 397 the humid regions of northern Iran are affected by Caspian atmospheric systems and various 398 western systems such as the Black Sea and the Mediterranean Sea; while the western and 399 southwestern regions of Iran (such as Shiraz, and Ahwaz) are only weakly affected by the two 400 systems of Saudi Arabia's high-pressure and Sudan's low-pressure. Susceptibility to a large 401 number of systems can disrupt the order of time series, reduce autocorrelation and consequently 402 lead to a poor prediction. This difference in the order of the ET0 series in different climates is 
depicted in the diagrams of Figure 9. On the other hand, these three stations of Shiraz, Ahwaz and Yazd, are located near the Subtropical High-Pressure Belt (SHPB) (latitude 30 degrees), which can stabilize the weather regime in these areas and thus make the ET0 series more regular. By moving away from the SHPB and approaching the latitudes of the northern humid regions, the effects of the irregularity of the annual regime become more obvious and can eventually lead to a relative increase in the prediction errors in these areas.

\section{Conclusion}

Studies have been shown that the water requirement of plants can be predicted with very good accuracy by using the time lags of the evapotranspiration variable. The currently used data-driven approaches could provide acceptable predictions of ET0, regardless of the various atmospheric and physical factors that affect it. This result is similar in all currently studied climates. Despite the significant improvement (about 16\%) of the ANFIS model in combination with the Differential Evolution optimization algorithm, it still fails to compete with the SARIMA linear model. The reason may be as Ashrafzadeh et al. (2020) has reported, the linear autocorrelation is stronger than nonlinear autocorrelation in the ET0 time series. Finally, the present study proposes time series models to better predict ET0 for two reasons: 1) higher accuracy 2) the simplicity of use. Another important conclusion of this paper is that the type of climate in a region significantly affects the accuracy of predictor models of ET0: In the arid and semi-arid climates of southern Iran, ET0 was predicted more accurately than the humid and sub-humid regions of northern Iran. Due to the high accuracy and promising results of the present study, the use of these data-driven models to predict the water needs of plants in other geographical areas is recommended. Moreover, the use of the current models especially SARIMA and the hybrid ANFIS-DE has research value for long-term and multi-ahead years prediction of monthly ET0. The use and comparison of stochastic, artificial 
426 intelligence, and metaheuristic models in predicting ET0 on a daily scale can be an interesting

427 topic for study, suggested to future researchers in this field.

428 Funding Statement

429 This work was supported by the Bu-Ali Sina University Deputy of Research (Grant numbers 99-

$430277)$.

431 Author's Contribution

432 Conceptualization, Pouya Aghelpour; methodology, Pouya Aghelpour, Vahid Varshavian;

433 software, Pouya Aghelpour, validation, Pouya Aghelpour, Vahid Varshavian, and Zahra Hamedi;

434 investigation, Pouya Aghelpour, and Vahid Varshavian; resources, Zahra Hamedi; data curation,

435 Pouya Aghelpour; writing — original draft preparation, Vahid Varshavian, Pouya Aghelpour, and 436 Zahra Hamedi; writing — review and editing, Vahid Varshavian, Pouya Aghelpour; visualization,

437 Zahra Hamedi; supervision, Vahid Varshavian. All authors have read and agreed to the published

438 version of the manuscript.

439 Ethics approval

440 Not applicable, because this article does not contain any studies with human or animal subjects.

441 Consent for publication

442 The Authors hereby consents to publication of the Work in any and all Springer publications

443 Data \& Code Availability

444 The data \& Code used to support the findings of this study are available from the first and

445 corresponding author upon request.

446 Conflicts of Interest

447 The authors declare that they have no conflicts of interest. 


\section{References}

1. Abrishami, N., Sepaskhah, A. R., \& Shahrokhnia, M. H. (2019). Estimating wheat and maize daily evapotranspiration using artificial neural network. Theoretical and Applied Climatology, 135(3), 945958. https://doi.org/10.1007/s00704-018-2418-4

2. Adamala, S., Raghuwanshi, N. S., \& Mishra, A. (2018). Development of generalized higher-order neural network-based models for estimating pan evaporation. In Hydrologic Modeling (pp. 55-71). Springer, Singapore. https://doi.org/10.1007/978-981-10-5801-1_5

3. Adnan, R. M., Malik, A., Kumar, A., Parmar, K. S., \& Kisi, O. (2019). Pan evaporation modeling by three different neuro-fuzzy intelligent systems using climatic inputs. Arabian Journal of Geosciences, 12(19), 1-14. https://doi.org/10.1007/s12517-019-4781-6

4. Aghelpour, P., Bahrami-Pichaghchi, H., \& Kisi, O. (2020a). Comparison of three different bio-inspired algorithms to improve ability of neuro fuzzy approach in prediction of agricultural drought, based on three different indexes. Computers and Electronics in Agriculture, 170, 105279. https://doi.org/10.1016/j.compag.2020.105279

5. Aghelpour, P., Bahrami-Pichaghchi, H., \& Varshavian, V. (2021a). Hydrological drought forecasting using multi-scalar streamflow drought index, stochastic models and machine learning approaches, in northern Iran. Stochastic Environmental Research and Risk Assessment, 1-21. https://doi.org/10.1007/s00477-020-01949-Z

6. Aghelpour, P., Guan, Y., Bahrami-Pichaghchi, H., Mohammadi, B., Kisi, O., \& Zhang, D. (2020b). Using the MODIS sensor for snow cover modeling and the assessment of drought effects on snow cover in a mountainous area. Remote Sensing, 12(20), 3437. https://doi.org/10.3390/rs12203437

7. Aghelpour, P., Kisi, O., \& Varshavian, V. (2021b). Multivariate Drought Forecasting in Short-and Long-Term Horizons Using MSPI and Data-Driven Approaches. Journal of Hydrologic Engineering, 26(4), 04021006. https://doi.org/10.1061/(ASCE)HE.1943-5584.0002059

8. Aghelpour, P., Mohammadi, B., \& Biazar, S. M. (2019). Long-term monthly average temperature forecasting in some climate types of Iran, using the models SARIMA, SVR, and SVR-FA. Theoretical and Applied Climatology, 138(3), 1471-1480. https://doi.org/10.1007/s00704-019-02905-w

9. Aghelpour, P., Mohammadi, B., Biazar, S. M., Kisi, O., \& Sourmirinezhad, Z. (2020c). A theoretical approach for forecasting different types of drought simultaneously, using entropy theory and machinelearning methods. ISPRS International Journal of Geo-Information, 9(12), 701. https://doi.org/10.3390/ijgi9120701

10. Aghelpour, P., Mohammadi, B., Mehdizadeh, S., Bahrami-Pichaghchi, H., \& Duan, Z. (2021c). A novel hybrid dragonfly optimization algorithm for agricultural drought prediction. Stochastic Environmental Research and Risk Assessment, 1-19. https://doi.org/10.1007/s00477-021-02011-2

11. Aghelpour, P., Singh, V. P., \& Varshavian, V. (2021d). Time series prediction of seasonal precipitation in Iran, using data-driven models: a comparison under different climatic conditions. Arabian Journal of Geosciences, 14(7), 1-14. https://doi.org/10.1007/s12517-021-06910-0

12. Aghelpour, P., \& Varshavian, V. (2020). Evaluation of stochastic and artificial intelligence models in modeling and predicting of river daily flow time series. Stochastic Environmental Research and Risk Assessment, 34(1), 33-50. https://doi.org/10.1007/s00477-019-01761-4

13. Aghelpour, P., \& Varshavian, V. (2021). Forecasting Different Types of Droughts Simultaneously Using Multivariate Standardized Precipitation Index (MSPI), MLP Neural Network, and Imperialistic Competitive Algorithm (ICA). Complexity, 2021. https://doi.org/10.1155/2021/6610228

14. Ahmadi, F., Mehdizadeh, S., Mohammadi, B., Pham, Q. B., Doan, T. N. C., \& Vo, N. D. (2021). Application of an artificial intelligence technique enhanced with intelligent water drops for monthly reference evapotranspiration estimation. Agricultural Water Management, 244, 106622. https://doi.org/10.1016/j.agwat.2020.106622

15. Allawi, M. F., Jaafar, O., Hamzah, F. M., Mohd, N. S., Deo, R. C., \& El-Shafie, A. (2018). Reservoir inflow forecasting with a modified coactive neuro-fuzzy inference system: a case study for a semi-arid 
region. Theoretical and Applied Climatology, 134(1), 545-563. https://doi.org/10.1007/s00704-0172292-5

16. Allen, R. G., Pereira, L. S., Raes, D., \& Smith, M. (1998). Crop evapotranspiration-Guidelines for computing crop evapotranspiration. Irrigation Drainage Paper, 56.

17. Ashrafzadeh, A., Ghorbani, M. A., Biazar, S. M., \& Yaseen, Z. M. (2019). Evaporation process modelling over northern Iran: application of an integrative data-intelligence model with the krill herd optimization algorithm. Hydrological Sciences Journal, 64(15), 1843-1856. https://doi.org/10.1080/02626667.2019.1676428

18. Ashrafzadeh, A., Kişi, O., Aghelpour, P., Biazar, S. M., \& Masouleh, M. A. (2020). Comparative study of time series models, support vector machines, and GMDH in forecasting long-term evapotranspiration rates in northern Iran. Journal of Irrigation and Drainage Engineering, 146(6), 04020010. https://doi.org/10.1061/(ASCE)IR.1943-4774.0001471

19. Ashrafzadeh, A., Malik, A., Jothiprakash, V., Ghorbani, M. A., \& Biazar, S. M. (2020). Estimation of daily pan evaporation using neural networks and meta-heuristic approaches. ISH Journal of Hydraulic Engineering, 26(4), 421-429. https://doi.org/10.1080/09715010.2018.1498754

20. Benmouiza, K., \& Cheknane, A. (2019). Clustered ANFIS network using fuzzy c-means, subtractive clustering, and grid partitioning for hourly solar radiation forecasting. Theoretical and Applied Climatology, 137(1), 31-43. https://doi.org/10.1007/s00704-018-2576-4

21. Bouznad, I. E., Guastaldi, E., Zirulia, A., Brancale, M., Barbagli, A., \& Bengusmia, D. (2020). Trend analysis and spatiotemporal prediction of precipitation, temperature, and evapotranspiration values using the ARIMA models: case of the Algerian Highlands. Arabian Journal of Geosciences, 13(24), 117. https://doi.org/10.1007/s12517-020-06330-6

22. Deo, R. C., Ghorbani, M. A., Samadianfard, S., Maraseni, T., Bilgili, M., \& Biazar, M. (2018). Multilayer perceptron hybrid model integrated with the firefly optimizer algorithm for windspeed prediction of target site using a limited set of neighboring reference station data. Renewable energy, 116, 309323. https://doi.org/10.1016/j.renene.2017.09.078

23. Falamarzi, Y., Palizdan, N., Huang, Y. F., \& Lee, T. S. (2014). Estimating evapotranspiration from temperature and wind speed data using artificial and wavelet neural networks (WNNs). Agricultural Water Management, 140, 26-36. https://doi.org/10.1016/j.agwat.2014.03.014

24. Gautam, R., \& Sinha, A. K. (2016). Time series analysis of reference crop evapotranspiration for Bokaro District, Jharkhand, India. Journal of Water and Land Development, 30(1), 51-56. http://dx.doi.org/10.1515/jwld-2016-0021

25. Guven, A., \& Kisi, O. (2013). Monthly pan evaporation modeling using linear genetic programming. Journal of Hydrology, 503, 178-185. https://doi.org/10.1016/j.jhydrol.2013.08.043

26. Halabi, L. M., Mekhilef, S., \& Hossain, M. (2018). Performance evaluation of hybrid adaptive neurofuzzy inference system models for predicting monthly global solar radiation. Applied energy, 213, 247261. https://doi.org/10.1016/j.apenergy.2018.01.035

27. Haznedar, B., \& Kalinli, A. (2016). Training ANFIS using genetic algorithm for dynamic systems identification. International Journal of Intelligent Systems and Applications in Engineering, 44-47. https://doi.org/10.18201/ijisae.266053

28. Jang, J. S. (1993). ANFIS: adaptive-network-based fuzzy inference system. IEEE transactions on systems, man, and cybernetics, 23(3), 665-685. https://doi.org/10.1109/21.256541

29. Karbasi, M. (2018). Forecasting of multi-step ahead reference evapotranspiration using waveletGaussian process regression model. Water resources management, 32(3), 1035-1052. https://doi.org/10.1007/s11269-017-1853-9

30. Keskin, M. E., Terzi, Ö., \& Taylan, D. (2009). Estimating daily pan evaporation using adaptive neuralbased fuzzy inference system. Theoretical and Applied climatology, 98(1), 79-87. https://doi.org/10.1007/s00704-008-0092-7

31. Khosravi, A., Nunes, R. O., Assad, M. E. H., \& Machado, L. (2018). Comparison of artificial intelligence methods in estimation of daily global solar radiation. Journal of cleaner production, 194, 342-358. https://doi.org/10.1016/j.jclepro.2018.05.147 
32. Kishore, V., \& Pushpalatha, M. (2017). Forecasting Evapotranspiration for Irrigation Scheduling using Neural Networks and ARIMA. International Journal of Applied Engineering Research, 12(21), 1084110847.

33. Kisi, O., Gorgij, A. D., Zounemat-Kermani, M., Mahdavi-Meymand, A., \& Kim, S. (2019). Drought forecasting using novel heuristic methods in a semi-arid environment. Journal of Hydrology, 578, 124053. https://doi.org/10.1016/j.jhydrol.2019.124053

34. Kumar, M., Raghuwanshi, N. S., Singh, R., Wallender, W. W., \& Pruitt, W. O. (2002). Estimating evapotranspiration using artificial neural network. Journal of Irrigation and Drainage Engineering, 128(4), 224-233. https://doi.org/10.1061/(ASCE)0733-9437(2002)128:4(224)

35. Landeras, G., Ortiz-Barredo, A., \& López, J. J. (2009). Forecasting weekly evapotranspiration with ARIMA and artificial neural network models. Journal of irrigation and drainage engineering, 135(3), 323-334. https://doi.org/10.1061/(ASCE)IR.1943-4774.0000008

36. Lucas, P. D. O., Alves, M. A., e Silva, P. C. D. L., \& Guimarães, F. G. (2020). Reference evapotranspiration time series forecasting with ensemble of convolutional neural networks. Computers and Electronics in Agriculture, 177, 105700. https://doi.org/10.1016/j.compag.2020.105700

37. Maroufpoor, S., Sanikhani, H., Kisi, O., Deo, R. C., \& Yaseen, Z. M. (2019). Long-term modelling of wind speeds using six different heuristic artificial intelligence approaches. International Journal of Climatology, 39(8), 3543-3557. https://doi.org/10.1002/joc.6037

38. Mekanik, F., Imteaz, M. A., \& Talei, A. (2016). Seasonal rainfall forecasting by adaptive networkbased fuzzy inference system (ANFIS) using large scale climate signals. Climate dynamics, 46(9-10), 3097-3111. https://doi.org/10.1007/s00382-015-2755-2

39. Moazenzadeh, R., \& Mohammadi, B. (2019). Assessment of bio-inspired metaheuristic optimisation algorithms for estimating soil temperature. Geoderma, 353, 152-171. https://doi.org/10.1016/j.geoderma.2019.06.028

40. Mohammadi, B., Guan, Y., Aghelpour, P., Emamgholizadeh, S., Pillco Zolá, R., \& Zhang, D. (2020). Simulation of Titicaca Lake Water Level Fluctuations Using Hybrid Machine Learning Technique Integrated with Grey Wolf Optimizer Algorithm. Water, 12(11), 3015. https://doi.org/10.3390/w12113015

41. Mohammadi, B., Guan, Y., Moazenzadeh, R., \& Safari, M. J. S. (2021). Implementation of hybrid particle swarm optimization-differential evolution algorithms coupled with multi-layer perceptron for $\begin{array}{lllll}\text { suspended sediment load estimation. } & \text { Catena, } & 105024 .\end{array}$ https://doi.org/10.1016/j.catena.2020.105024

42. Mohammadi, B., \& Mehdizadeh, S. (2020). Modeling daily reference evapotranspiration via a novel approach based on support vector regression coupled with whale optimization algorithm. Agricultural Water Management, 237, 106145. https://doi.org/10.1016/j.agwat.2020.106145

43. Mossad, A., \& Alazba, A. A. (2016). Simulation of temporal variation for reference evapotranspiration under arid climate. Arabian Journal of Geosciences, 9(5), 386. https://doi.org/10.1007/s12517-0162482-y

44. Pham, Q. B., Sammen, S. S., Abba, S. I., Mohammadi, B., Shahid, S., \& Abdulkadir, R. A. (2021). A new hybrid model based on relevance vector machine with flower pollination algorithm for phycocyanin pigment concentration estimation. Environmental Science and Pollution Research, 1-16. https://doi.org/10.1007/s11356-021-12792-2

45. Psilovikos, A., \& Elhag, M. (2013). Forecasting of remotely sensed daily evapotranspiration data over Nile Delta region, Egypt. Water resources management, 27(12), 4115-4130. https://doi.org/10.1007/s11269-013-0368-2

46. Rahimi, J., Ebrahimpour, M., \& Khalili, A. (2013). Spatial changes of extended De Martonne climatic zones affected by climate change in Iran. Theoretical and applied climatology, 112(3), 409-418. https://doi.org/10.1007/s00704-012-0741-8

47. Salas, J. D. (1980). Applied modeling of hydrologic time series. Water Resources Publication. 
48. Storn, R., \& Price, K. (1997). Differential evolution-a simple and efficient heuristic for global optimization over continuous spaces. Journal of global optimization, 11(4), 341-359. https://doi.org/10.1023/A:1008202821328

49. Üstün, İ., Üneş, F., Mert, İ., \& Karakuş, C. (2020). A comparative study of estimating solar radiation using machine learning approaches: DL, SMGRT, and ANFIS. Energy Sources, Part A: Recovery, Utilization, and Environmental Effects, 1-24. https://doi.org/10.1080/15567036.2020.1781301

50. Yaseen, Z. M., Ghareb, M. I., Ebtehaj, I., Bonakdari, H., Siddique, R., Heddam, S., ... \& Deo, R. (2018). Rainfall pattern forecasting using novel hybrid intelligent model based ANFIS-FFA. Water resources management, 32(1), 105-122. https://doi.org/10.1007/s11269-017-1797-0 
Table 1. The studied stations' location, climate (according to extended De-Martonne classification [Rahimi et al., 2013]) and the main agricultural/horticultural products of their regions

\begin{tabular}{|c|c|c|c|c|c|c|c|}
\hline \multirow{2}{*}{ Province } & \multirow{2}{*}{ Station } & \multicolumn{3}{|c|}{ Coordinates } & \multirow{2}{*}{$\begin{array}{c}\text { Climate } \\
\text { (based on } \\
\text { extended De- } \\
\text { Martonne } \\
\text { method) }\end{array}$} & \multicolumn{2}{|c|}{ Main products } \\
\hline & & $\begin{array}{l}\text { Latitude - } \\
\text { northern } \\
\text { (degree) }\end{array}$ & $\begin{array}{l}\text { Longitude - } \\
\text { eastern } \\
\text { (degree) }\end{array}$ & $\begin{array}{l}\text { Elevation } \\
\text { (m) }\end{array}$ & & Agricultural & Horticultural \\
\hline Gilan & $\begin{array}{l}\text { Bandar } \\
\text { Anzali }\end{array}$ & 37.47 & 49.47 & -26.2 & $\begin{array}{l}\text { Per humid(B) } \\
\text { - Moderate }\end{array}$ & $\begin{array}{l}\text { rice cultivars; } \\
\text { tobacco; } \\
\text { watermelon }\end{array}$ & $\begin{array}{l}\text { tea; olive; citrus; } \\
\text { kiwi; plum }\end{array}$ \\
\hline \multirow[t]{2}{*}{ Mazandaran } & Ramsar & 36.90 & 50.67 & -20.0 & $\begin{array}{c}\text { Per } \\
\text { humid(A) - } \\
\text { Moderate }\end{array}$ & \multirow{2}{*}{$\begin{array}{l}\text { rice cultivars; } \\
\text { wheat; soy; } \\
\text { rapeseed }\end{array}$} & \multirow{2}{*}{$\begin{array}{c}\text { citrus; kiwi; } \\
\text { ornamental flower; } \\
\text { plants }\end{array}$} \\
\hline & Gharakhil & 36.45 & 52.77 & 14.7 & $\begin{array}{l}\text { Sub-humid - } \\
\text { Moderate }\end{array}$ & & \\
\hline Khuzestan & Ahwaz & 31.33 & 48.67 & 22.5 & Arid - Warm & $\begin{array}{l}\text { wheat; barley; } \\
\text { maize; legumes; } \\
\text { rapeseed }\end{array}$ & $\begin{array}{c}\text { vegetable; } \\
\text { cucurbits; potato; } \\
\text { onion }\end{array}$ \\
\hline Fars & Shiraz & 29.53 & 52.60 & 1484.0 & $\begin{array}{l}\text { Semi arid - } \\
\text { Moderate }\end{array}$ & $\begin{array}{c}\text { wheat; barley; } \\
\text { sugar beet; maize }\end{array}$ & $\begin{array}{l}\text { almonds, grapes, } \\
\text { pomegranates, } \\
\text { damask rose; figs }\end{array}$ \\
\hline Yazd & Yazd & 31.90 & 54.28 & 1237.2 & $\begin{array}{l}\text { Extra arid - } \\
\quad \text { Cold }\end{array}$ & $\begin{array}{l}\text { sorghum, fodder } \\
\text { maize, millet, } \\
\text { legumes, alfalfa }\end{array}$ & $\begin{array}{c}\text { pistachios, } \\
\text { pomegranates, } \\
\text { apricots, saffron }\end{array}$ \\
\hline
\end{tabular}


Table 2. Specifications of the meteorological data used and the calculated ET0 on monthly scale

\begin{tabular}{|c|c|c|c|c|c|c|c|c|c|}
\hline \multirow{2}{*}{ Station } & \multirow{2}{*}{ Variable } & \multicolumn{4}{|c|}{ Training period } & \multicolumn{4}{|c|}{ Testing Period } \\
\hline & & Min.* & Max. & Average & STD. & Min. & Max. & Average & STD. \\
\hline \multirow[t]{7}{*}{ Bandar Anzali } & $\operatorname{Tmin}\left({ }^{\circ} \mathrm{C}\right)$ & 0.80 & 25.40 & 14.41 & 6.85 & 3.10 & 26.10 & 14.80 & 6.84 \\
\hline & $\operatorname{Tmax}\left({ }^{\circ} \mathrm{C}\right)$ & 5.30 & 31.80 & 19.24 & 7.14 & 8.40 & 32.80 & 20.12 & 7.57 \\
\hline & Tmean $\left({ }^{\circ} \mathrm{C}\right)$ & 3.00 & 28.40 & 16.82 & 6.99 & 5.80 & 29.30 & 17.46 & 7.18 \\
\hline & $\mathrm{RHmax}(\%)$ & 81.20 & 96.90 & 92.21 & 3.09 & 81.50 & 96.50 & 91.68 & 3.73 \\
\hline & RHmin $(\%)$ & 54.80 & 84.10 & 73.11 & 5.72 & 53.90 & 84.40 & 71.76 & 7.04 \\
\hline & $\operatorname{SSD}\left(\frac{h r}{\text { month }}\right)$ & 28.50 & 337.60 & 161.74 & 73.68 & 40.40 & 339.70 & 163.78 & 82.92 \\
\hline & ET0 $\left(\frac{\mathrm{mm}}{\text { month }}\right)$ & 20.60 & 174.30 & 74.39 & 43.57 & 22.70 & 170.30 & 80.42 & 49.65 \\
\hline \multirow[t]{7}{*}{ Ramsar } & $\operatorname{Tmin}\left({ }^{\circ} \mathrm{C}\right)$ & 0.90 & 24.90 & 13.77 & 6.82 & 2.90 & 25.40 & 14.34 & 6.85 \\
\hline & $\operatorname{Tmax}\left({ }^{\circ} \mathrm{C}\right)$ & 7.10 & 31.50 & 19.93 & 6.86 & 9.20 & 32.50 & 20.43 & 7.23 \\
\hline & Tmean $\left({ }^{\circ} \mathrm{C}\right)$ & 4.00 & 28.20 & 16.86 & 6.82 & 6.10 & 28.90 & 17.39 & 7.03 \\
\hline & RHmax (\%) & 80.60 & 97.30 & 89.85 & 3.33 & 80.30 & 95.10 & 90.18 & 3.80 \\
\hline & RHmin $(\%)$ & 56.50 & 84.20 & 69.07 & 4.83 & 56.70 & 82.70 & 69.61 & 5.82 \\
\hline & $\operatorname{SSD}\left(\frac{h r}{\text { month }}\right)$ & 39.00 & 289.20 & 139.53 & 51.16 & 52.80 & 309.70 & 140.29 & 58.79 \\
\hline & ET0 $\left(\frac{\mathrm{mm}}{\text { month }}\right)$ & 20.90 & 158.50 & 71.52 & 37.90 & 23.20 & 151.70 & 72.77 & 42.10 \\
\hline \multirow[t]{7}{*}{ Gharakhil } & $\operatorname{Tmin}\left({ }^{\circ} \mathrm{C}\right)$ & -1.30 & 23.80 & 12.76 & 7.14 & 1.50 & 24.20 & 13.03 & 7.20 \\
\hline & $\operatorname{Tmax}\left({ }^{\circ} \mathrm{C}\right)$ & 8.10 & 34.80 & 21.98 & 7.14 & 11.70 & 34.70 & 22.58 & 7.35 \\
\hline & Tmean $\left({ }^{\circ} \mathrm{C}\right)$ & 3.40 & 28.80 & 17.37 & 7.11 & 6.60 & 29.20 & 17.80 & 7.26 \\
\hline & RHmax (\%) & 89.40 & 98.90 & 95.40 & 2.04 & 89.20 & 97.00 & 94.16 & 2.07 \\
\hline & RHmin (\%) & 46.50 & 76.90 & 62.45 & 5.59 & 47.60 & 73.50 & 62.27 & 5.41 \\
\hline & $\operatorname{SSD}\left(\frac{h r}{\text { month }}\right)$ & 40.30 & 310.20 & 170.11 & 49.43 & 73.30 & 317.60 & 169.54 & 53.09 \\
\hline & ET0 $\left(\frac{\mathrm{mm}}{\text { month }}\right)$ & 23.40 & 164.40 & 78.10 & 40.16 & 20.20 & 169.70 & 80.22 & 44.70 \\
\hline \multirow[t]{7}{*}{ Ahwaz } & $\operatorname{Tmin}\left({ }^{\circ} \mathrm{C}\right)$ & 6.20 & 31.50 & 19.44 & 7.86 & 7.40 & 31.40 & 19.79 & 8.02 \\
\hline & $\operatorname{Tmax}\left({ }^{\circ} \mathrm{C}\right)$ & 14.70 & 48.10 & 33.60 & 10.59 & 17.40 & 48.90 & 34.15 & 10.24 \\
\hline & Tmean $\left({ }^{\circ} \mathrm{C}\right)$ & 10.40 & 39.80 & 26.52 & 9.20 & 13.40 & 39.90 & 26.98 & 9.10 \\
\hline & RHmax (\%) & 28.10 & 95.80 & 60.09 & 19.00 & 27.80 & 96.30 & 62.35 & 18.27 \\
\hline & RHmin (\%) & 6.80 & 67.10 & 23.85 & 14.67 & 7.80 & 64.70 & 25.46 & 13.46 \\
\hline & $\operatorname{SSD}\left(\frac{h r}{\text { month }}\right)$ & 162.40 & 383.60 & 273.79 & 58.02 & 163.60 & 370.30 & 272.99 & 58.36 \\
\hline & ET0 $\left(\frac{\text { month }}{\text { month }}\right)$ & 40.20 & 354.50 & 169.06 & 93.21 & 44.80 & 310.50 & 161.89 & 85.55 \\
\hline \multirow[t]{7}{*}{ Shiraz } & $\operatorname{Tmin}\left({ }^{\circ} \mathrm{C}\right)$ & -2.00 & 24.20 & 10.95 & 7.46 & -1.10 & 22.30 & 10.46 & 7.29 \\
\hline & $\operatorname{Tmax}\left({ }^{\circ} \mathrm{C}\right)$ & 9.40 & 40.10 & 26.33 & 9.17 & 11.70 & 40.10 & 26.90 & 8.85 \\
\hline & Tmean $\left({ }^{\circ} \mathrm{C}\right)$ & 4.80 & 32.10 & 18.64 & 8.26 & 5.60 & 31.10 & 18.68 & 8.04 \\
\hline & RHmax (\%) & 30.00 & 91.90 & 58.33 & 17.96 & 27.80 & 90.90 & 58.51 & 18.24 \\
\hline & RHmin (\%) & 6.60 & 54.50 & 20.86 & 11.01 & 4.30 & 49.50 & 17.51 & 10.04 \\
\hline & $\operatorname{SSD}\left(\frac{h r}{\text { month }}\right)$ & 208.50 & 372.30 & 296.88 & 40.68 & 222.70 & 370.30 & 294.97 & 40.10 \\
\hline & ET0 $\left(\frac{m \text { mm }}{m o n t h}\right)$ & 37.90 & 251.40 & 133.79 & 64.01 & 44.70 & 224.50 & 129.44 & 60.15 \\
\hline \multirow[t]{7}{*}{ Yazd } & $\operatorname{Tmin}\left({ }^{\circ} \mathrm{C}\right)$ & -4.40 & 28.30 & 13.24 & 8.74 & 1.10 & 27.40 & 14.32 & 8.46 \\
\hline & $\operatorname{Tmax}\left({ }^{\circ} \mathrm{C}\right)$ & 4.80 & 42.60 & 27.33 & 9.62 & 12.40 & 41.80 & 27.87 & 9.05 \\
\hline & Tmean $\left({ }^{\circ} \mathrm{C}\right)$ & 0.20 & 35.50 & 20.29 & 9.16 & 6.80 & 34.60 & 21.10 & 8.74 \\
\hline & $\mathrm{RHmax}(\%)$ & 15.50 & 87.70 & 41.06 & 19.22 & 12.60 & 80.40 & 38.11 & 17.38 \\
\hline & RHmin (\%) & 5.10 & 57.60 & 16.25 & 9.96 & 4.90 & 39.60 & 14.49 & 7.54 \\
\hline & $\operatorname{SSD}\left(\frac{h r}{\text { month }}\right)$ & 209.80 & 376.80 & 292.77 & 47.08 & 200.40 & 383.00 & 296.97 & 47.65 \\
\hline & ET0 $\left(\frac{\mathrm{mm}}{\text { month }}\right)$ & 34.00 & 289.10 & 156.13 & 73.86 & 55.30 & 273.50 & 155.87 & 70.35 \\
\hline
\end{tabular}

*Min. = Minimum; Max. $=$ Maximum; STD = Standard deviation 
Table 3. The operators of differential evolution Algorithm

\begin{tabular}{cc}
\hline Operator & Value \\
\hline Population & 100 \\
Maximum Number of Iterations & 200 \\
Crossover probability & 0.1 \\
Scaling factor lower bound & 0.2 \\
Scaling factor upper bound & 0.8 \\
\hline
\end{tabular}


Table 4. Evaluating the models' predictions by evaluation criteria

\begin{tabular}{|c|c|c|c|c|c|c|c|}
\hline \multirow{2}{*}{ Station } & \multirow{2}{*}{ Model } & \multicolumn{3}{|c|}{ Train } & \multicolumn{3}{|c|}{ Test } \\
\hline & & $\begin{array}{l}\text { RMSE } \\
\left(\frac{\mathrm{mm}}{\text { month }}\right)\end{array}$ & PB & $\mathrm{R}$ & $\begin{array}{l}\text { RMSE } \\
\left(\frac{\mathrm{mm}}{\mathrm{month}}\right)\end{array}$ & PB & $\mathrm{R}$ \\
\hline \multirow{3}{*}{ Bandar Anzali } & SARIMA $(1,0,0)(2,1,2)_{12}{ }^{*}$ & 9.436 & -0.026 & 0.977 & 10.078 & -0.042 & 0.982 \\
\hline & ANFIS & 8.177 & -0.014 & 0.983 & 12.767 & 0.035 & 0.970 \\
\hline & ANFIS-DE & 10.492 & -0.019 & 0.971 & 10.532 & -0.018 & 0.977 \\
\hline \multirow{3}{*}{ Ramsar } & SARIMA $(1,0,2)(3,1,3)_{12}$ & 8.973 & -0.011 & 0.973 & 9.711 & -0.028 & 0.975 \\
\hline & ANFIS & 8.130 & -0.011 & 0.977 & 13.257 & -0.013 & 0.949 \\
\hline & ANFIS-DE & 11.171 & -0.015 & 0.957 & 10.998 & -0.013 & 0.965 \\
\hline \multirow{3}{*}{ Gharakhil } & SARIMA $(1,0,0)(3,1,1)_{12}$ & 10.909 & -0.013 & 0.963 & 9.713 & -0.041 & 0.979 \\
\hline & ANFIS & 9.624 & -0.014 & 0.971 & 12.569 & -0.018 & 0.960 \\
\hline & ANFIS-DE & 12.300 & -0.018 & 0.953 & 10.711 & -0.005 & 0.970 \\
\hline \multirow{3}{*}{ Ahwaz } & SARIMA $(1,0,1)(2,1,3)_{12}$ & 14.844 & -0.003 & 0.987 & 12.789 & 0.020 & 0.990 \\
\hline & ANFIS & 12.597 & -0.008 & 0.991 & 16.906 & -0.021 & 0.983 \\
\hline & ANFIS-DE & 16.134 & -0.008 & 0.984 & 14.533 & -0.020 & 0.985 \\
\hline \multirow{3}{*}{ Shiraz } & SARIMA $(1,0,1)(2,1,2)_{12}$ & 8.364 & -0.004 & 0.991 & 7.918 & 0.013 & 0.992 \\
\hline & ANFIS & 6.281 & -0.004 & 0.995 & 9.920 & -0.007 & 0.986 \\
\hline & ANFIS-DE & 10.408 & -0.009 & 0.987 & 9.077 & -0.014 & 0.988 \\
\hline \multirow{3}{*}{ Yazd } & SARIMA $(2,0,0)(3,1,3)_{12}$ & 10.142 & -0.007 & 0.991 & $\mathbf{8 . 8 9 7}$ & 0.005 & 0.994 \\
\hline & ANFIS & 8.858 & -0.008 & 0.993 & 10.537 & 0.007 & 0.989 \\
\hline & ANFIS-DE & 11.224 & -0.011 & 0.989 & 9.548 & 0.000 & 0.991 \\
\hline
\end{tabular}

*Bold rows specify the best fitted model in each station. 


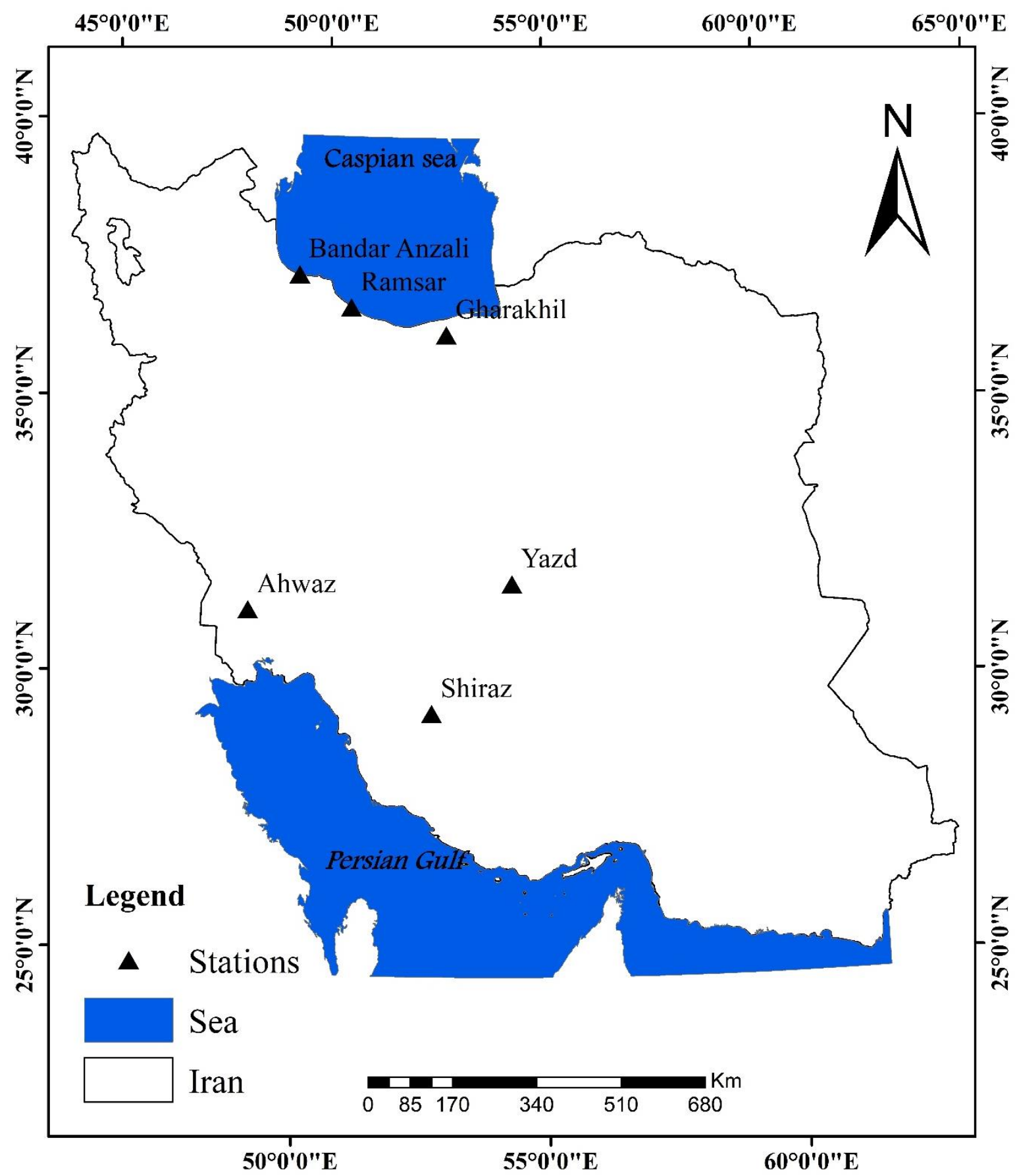

Figure 1. Location of the stations under investigation on the country 


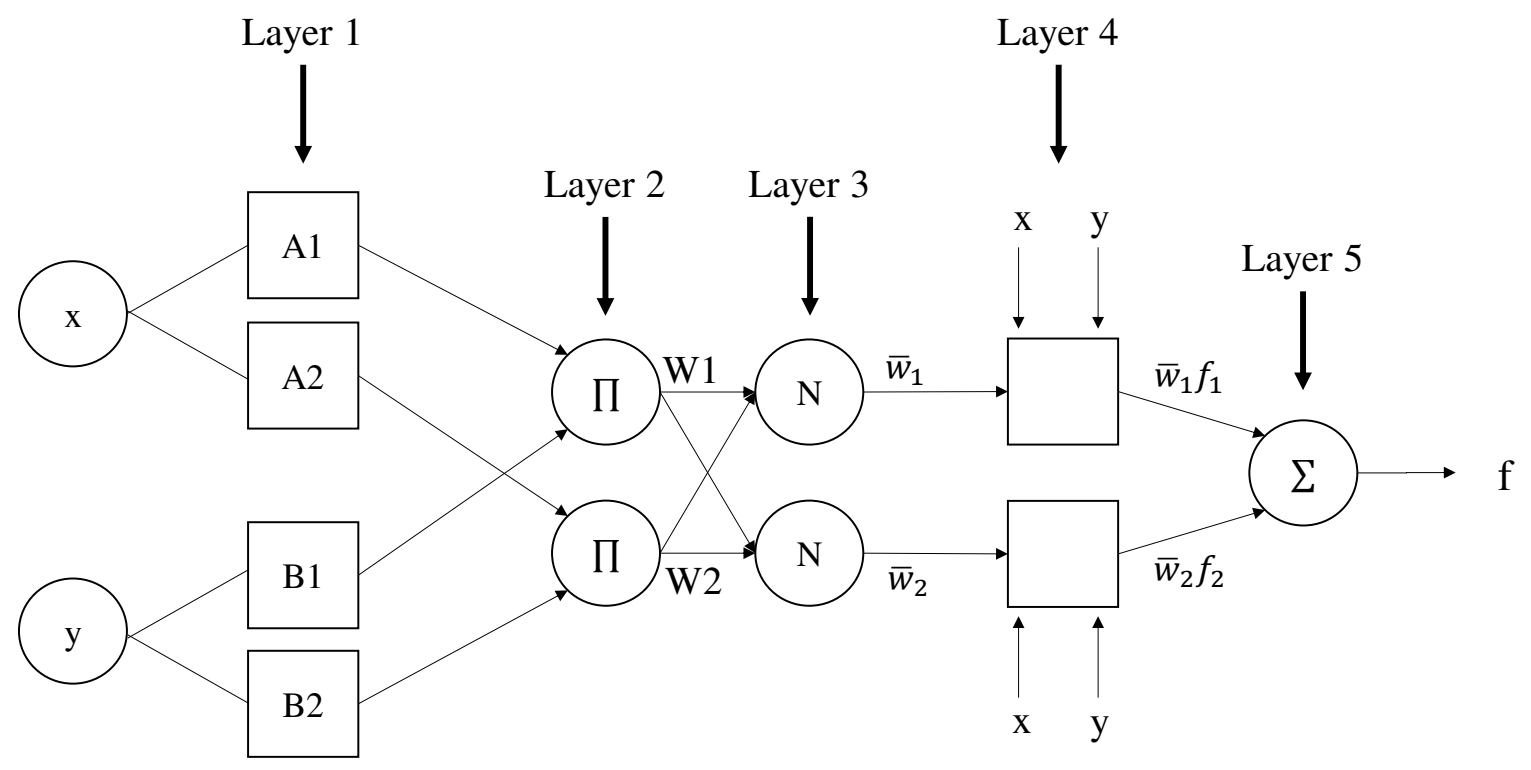

Figure 2. The schematic structure of an ANFIS model with two inputs 


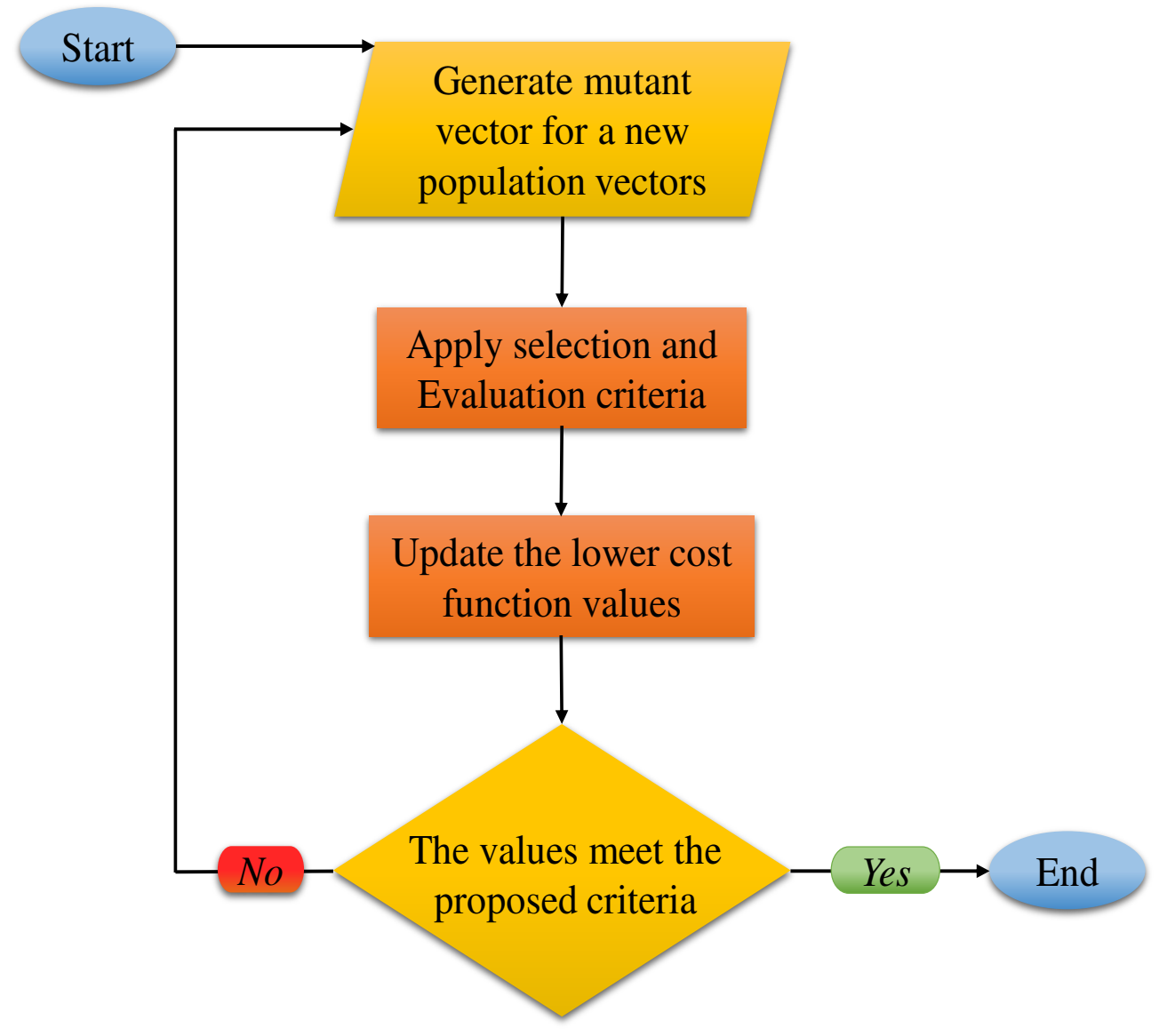

Figure 3. Flowchart of the optimization process based on differential evolution algorithm 


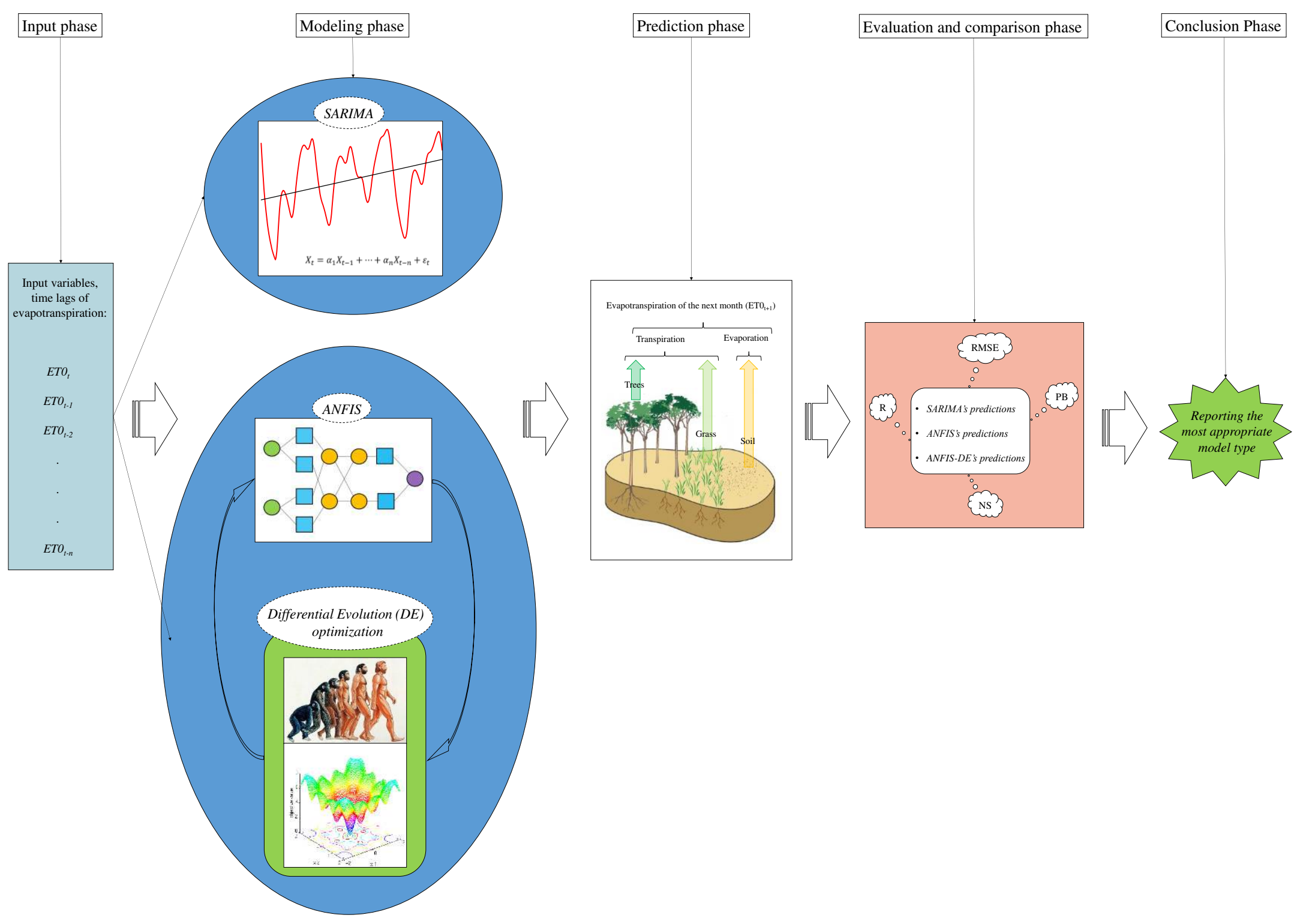

Figure 4. General flowchart of the evapotranspiration modeling, prediction and evaluation processes 

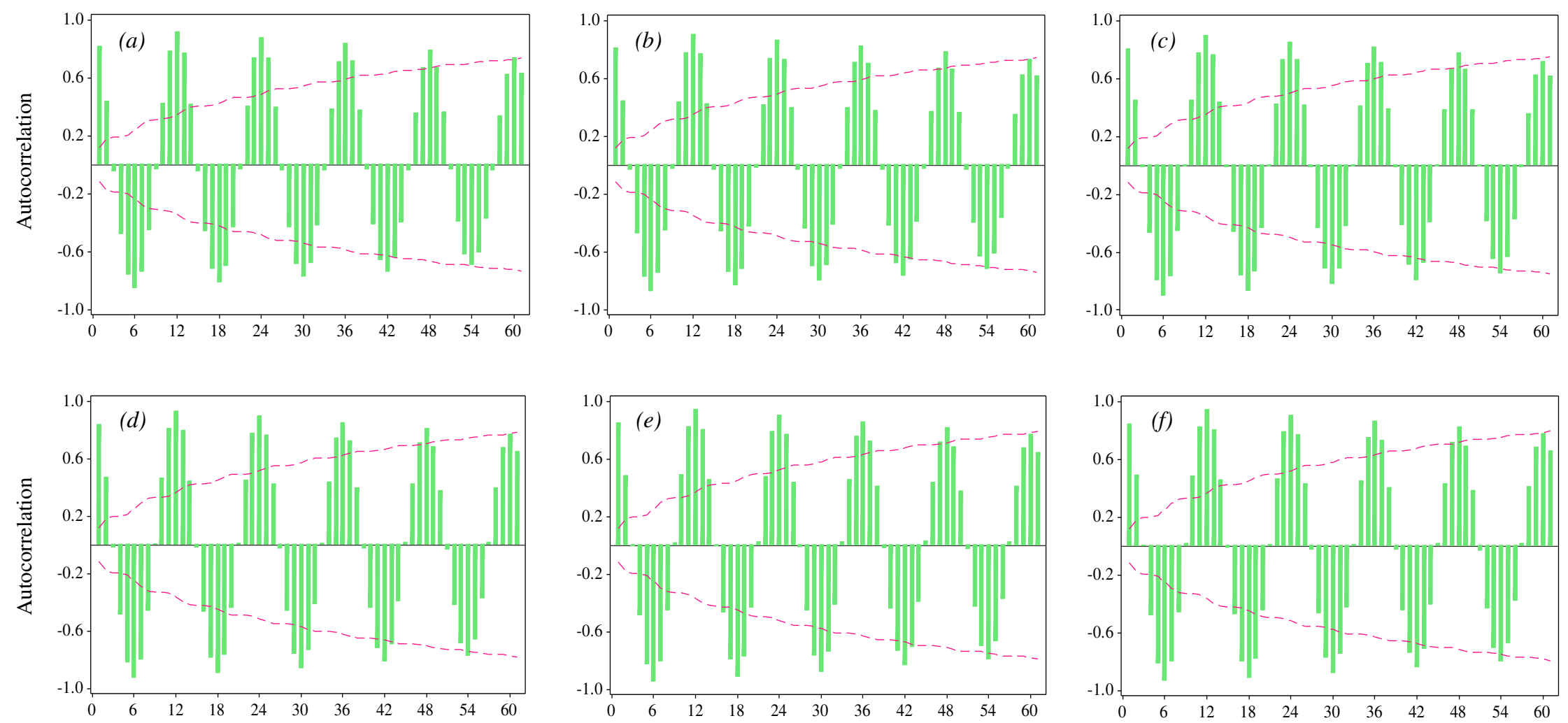

Time lag (month)

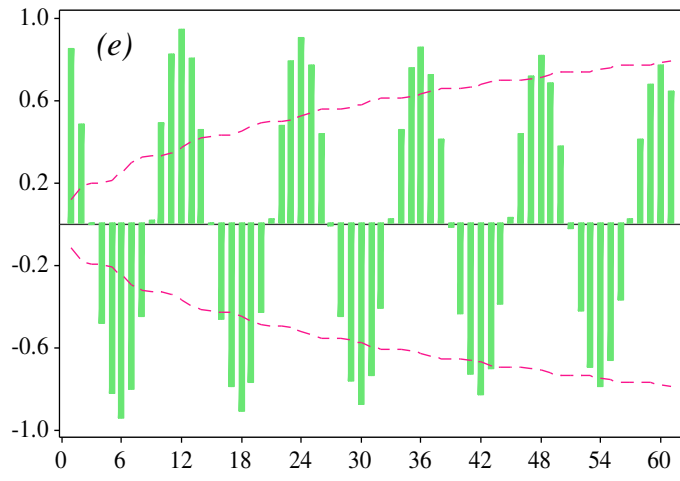

Time lag (month)

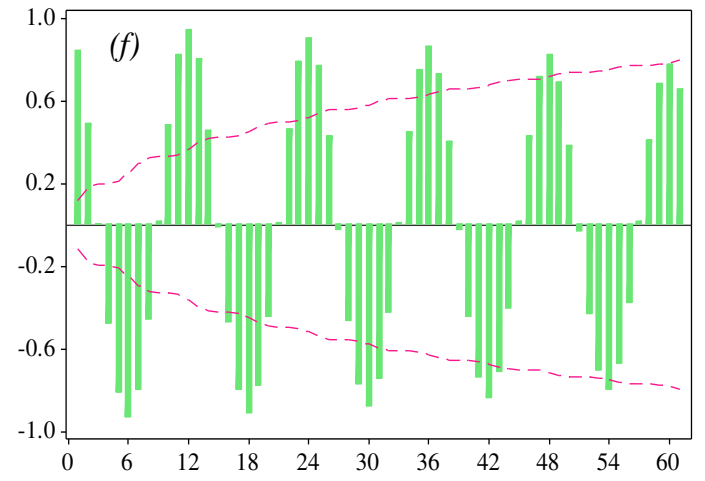

Time lag (month)

Figure 5. Autocorrelation plots for the monthly ET0 time series; the alphabets within the brackets refer to the stations: (a) Bandar Anzali, (b) Ramsar, (c) Gharakhil, (d) Ahwaz, (e) Shiraz, (f) Yazd 

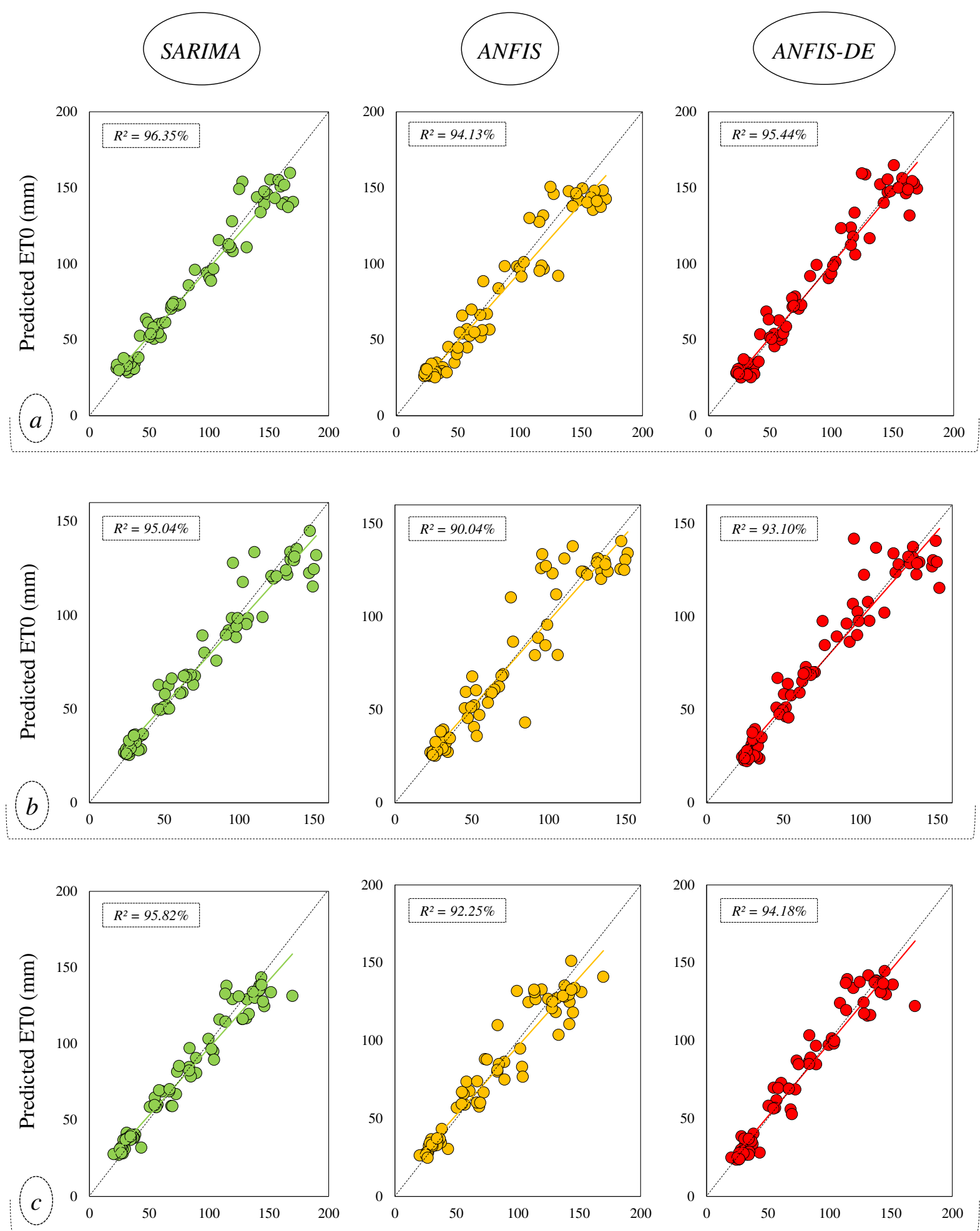

Figure 6. Scatter plots to investigate the models' predictions against their simultaneous observed values; the alphabets within the brackets refer to the stations: (a) Bandar Anzali, (b) Ramsar, (c) Gharakhil, (d) Ahwaz, (e) Shiraz, (f) Yazd 

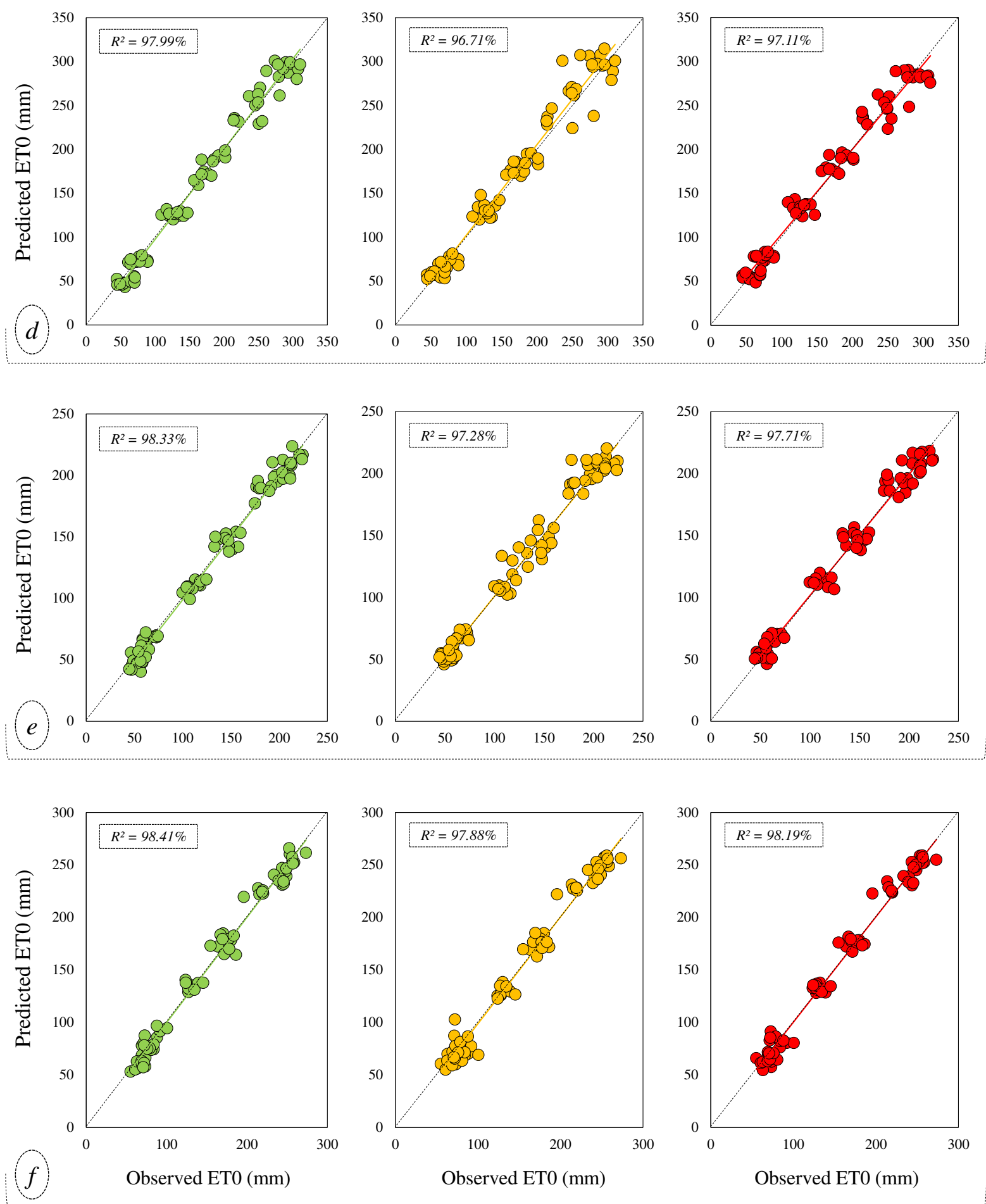

Figure 6. Continued 

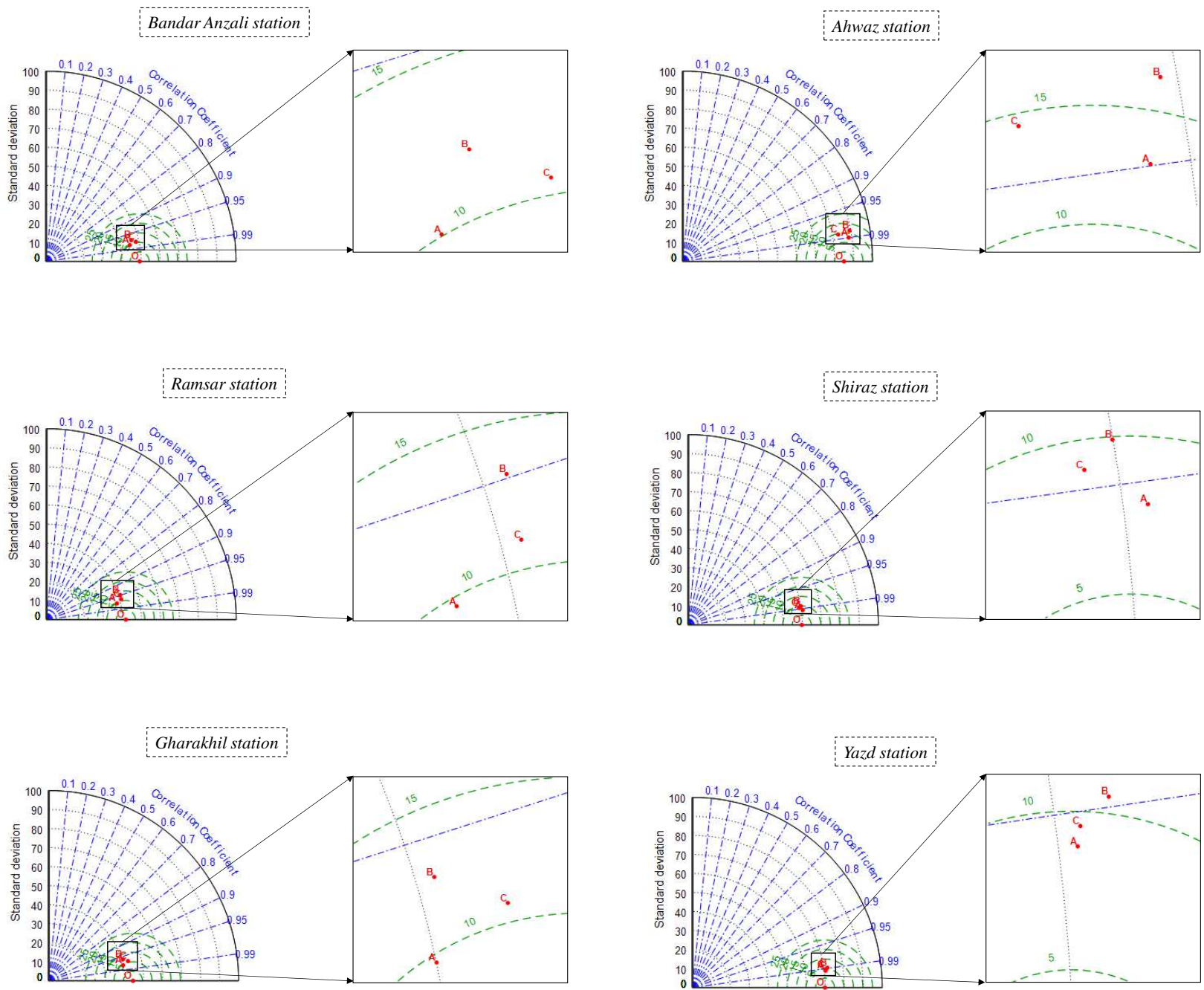

\begin{tabular}{|c|c|c|c|c|}
\hline$\bullet(\mathrm{O})$ & $\bullet(\mathrm{A})$ & $\bullet(\mathrm{B})$ & $\bullet(\mathrm{C})$ & $----\cdot$ \\
\hline Observational ET0 & Predicted ET0 by SARIMA & Predicted ET0 by ANFIS & Predicted ET0 by ANFIS-DE & RMSE limits \\
\hline
\end{tabular}

Figure 7. Taylor diagrams to compare the models in the stations; the diagram of each station is specified by its own name 

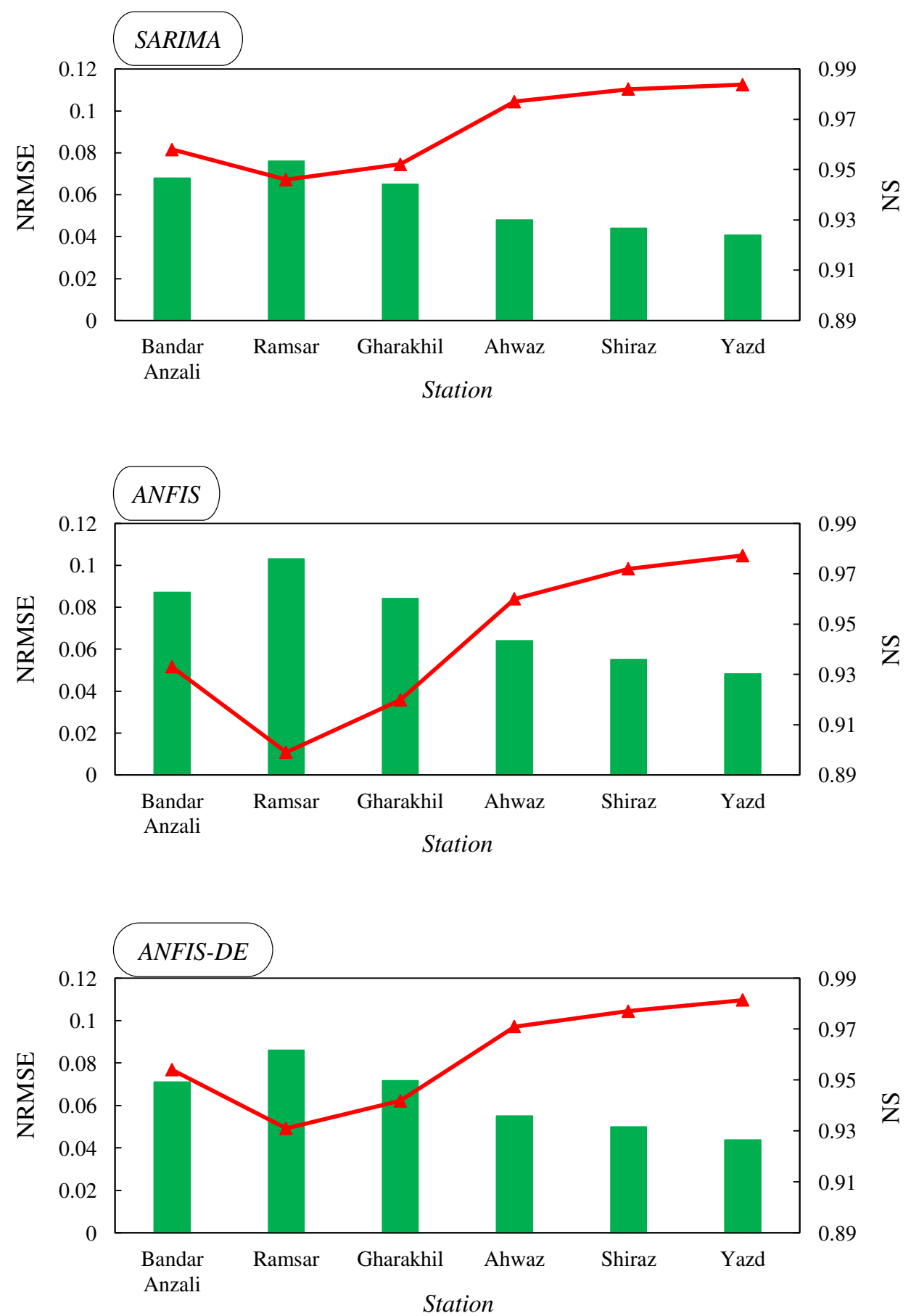

NRMSE $\simeq \mathrm{NS}$

Figure 8. Combo-graph of NRMSE and NS criteria to make a comparison between the different climates 

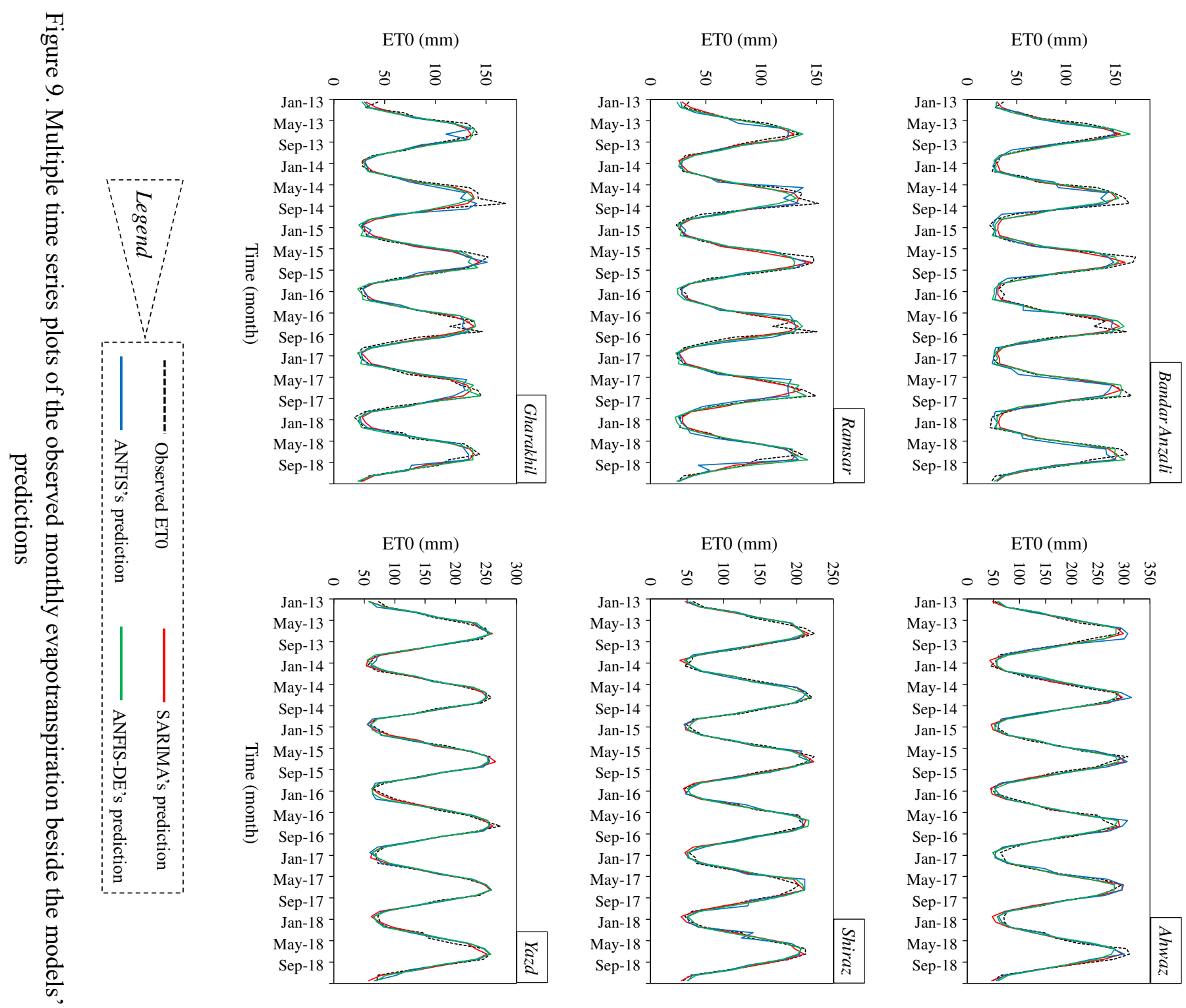

ET0 (mm)
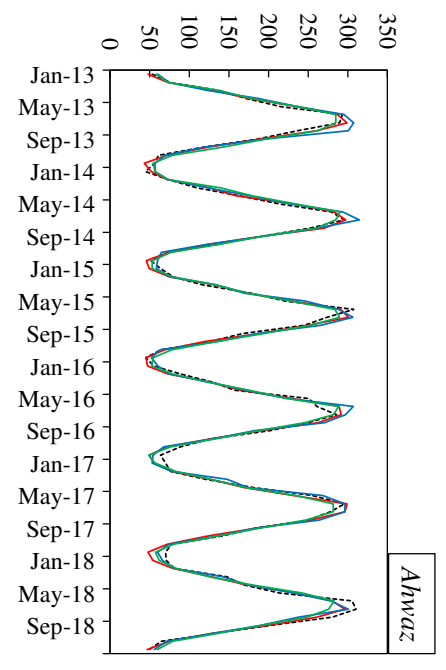